\title{
VARIANTES DE LA ORALIDAD ELABORADA EN LA SEGUNDA MITAD DEL SIGLO XIX: DOS TRADUCGIONES COETÁNEAS DE LOS CAUTIVOS DE PLAUTO*
}

\author{
Santiago Del Rey QuesadA \\ Universidad de Sevilla
}

\section{RESUMEN}

Los estudios dedicados a la búsqueda de las huellas de la oralidad en lo escrito se han afanado en rastrear y describir fenómenos característicos de la inmediatez comunicativa en diferentes épocas y tradiciones discursivas. El trabajo que presento aquí se decanta por el concepto de oralidad elaborada para dar cuenta del diferente perfil concepcional que asumen las estrategias de oralización en la literatura. Trato de definir este concepto y de ejemplificarlo a partir de dos traducciones decimonónicas de Los Cautivos de Plauto, analizando diferentes estrategias sintáctico-discursivas que considero muy representativas de este tipo de oralidad y tratando de establecer las similitudes y las divergencias entre las dos versiones.

PALABRAS ClAVE: oralidad fingida, traducción, tradición discursiva, sintaxis, estructura informativa, español moderno.

\section{AbSTRACT}

Those researchers working on fictional orality have usually tried to find and describe phenomena which can be considered to be typical of communicative immediacy at different periods of the Spanish language and in distinct discourse traditions. In this paper, I opt for the concept of elaborated orality, which highlights the fact that strategies of oralization in literature show a different conceptional profile-according to Koch \& Oesterreicher's $(1985,1990)$ proposal. Two 19th-century

* Este trabajo forma parte del proyecto de investigación «Tradicionalidad discursiva e idiomática, sintaxis del discurso, traducción y cambio lingüístico en la historia del español moderno: prosa (pre-) periodística/ensayística y literaria» (PGC2018-097823-B-100). Agradezco encarecidamente a Antonio Narbona y a Rafael Cano los atinados comentarios y las lúcidas reflexiones que compartieron conmigo tras la lectura del borrador de este artículo. Expreso también mi agradecimiento a los dos revisores anónimos de Oralia que con sus oportunísimas críticas y sabias palabras al hilo de la lectura del artículo han contribuido a mejorar considerablemente el contenido original. 
translations of Plautus' Captivi constitute the corpus of this study in which some discourse-based syntactic strategies are analyzed with the aim of defining and exemplifying this elaborated orality in the two translations in question, while also spelling out the similarities and divergences between both texts.

KEYWORDS: fictional orality, translation, discourse tradition, syntax, informative structure, modern Spanish.

Fecha de recepción: 30/04/2018

\section{El LABERINTO MÁGICO DE LA ORALIDAD}

En vano intentaríamos realizar un estado de la cuestión exhaustivo que abarcara todos los estudios publicados en las últimas décadas en torno al problema de la oralidad y de su relación con otros conceptos vinculados a lo coloquial, lo conversacional o lo dialógico ${ }^{1}$. Solamente el aspecto que nos compete en este trabajo, el de la oralidad en lo escrito, ha despertado un enorme interés en los últimos años. La fascinación que algunos investigadores, entre los que me incluyo, han sentido por descubrir huellas de la oralidad (cf. Oesterreicher 1996: 323) en textos antiguos -y no solo en estos- tiene probablemente que ver con el carácter «mágico» que Johannes Kabatek atribuye a este campo de investigación ${ }^{2}$ : intentar hallar elementos de la conversación real en textos antiguos convierte al lingüista en una especie de arqueólogo que se embarca en una aventura tan gratificante como arriesgada. Mi incursión en esta aventura, que empezó con mi proyecto de tesis doctoral hace ya casi una década, se debe en gran parte a la lectura de numerosos trabajos de José Jesús de Bustos Tovar, cuyos entusiasmo y prudencia, unidos al rigor teórico y metodológico impuesto en su producción académica, intentaré emular en este artículo que dedico a la memoria de su magisterio y de su amistad.

La vasta producción bibliográfica a la que he aludido me exime de justificar por extenso el marco teórico que asumiré para el análisis del apartado §3. Se trata del marco que la mayoría de estudiosos pertenecientes a la tradición romanística europea utiliza para inscribir los estudios sobre las relaciones entre oralidad y escrituralidad en diferentes ámbitos de análisis

\footnotetext{
1 Para la discusión del problema terminológico en el dominio hispanohablante, remito a López Serena (2007a: 191-209) y a Del Rey (2011a: 696-702; 2015a: 65-69).

2 «Todo lo desconocido, todo lo que ocurre pero que no se ve, todo lo que está en estado latente o en otro estado supuesto pero inaccesible, se encuentra en la oralidad. Máxima tarea, pues, del historiador de la lengua la de la reconstrucción de la oralidad de épocas pasadas» (Kabatek 2012: 38).
} 
y subdisciplinas lingüísticas: el elaborado hace ya más de treinta años por Peter Koch y Wulf Oesterreicher ${ }^{3}$. La distinción fundamental que estos autores realizan entre el medio de producción de los discursos (fónico/gráfico) y la concepción (hablado/escrito) ha contribuido a abordar el análisis de diferentes fenómenos discursivos de forma muy rentable y razonable. Concepcionalmente, la oposición entre lo hablado y lo escrito se concibe como un continuum a través del que se mueve todo tipo de discursos, condicionados por diferentes parámetros situacionales. Asimismo, su modelo de la cadena de variedades ha servido para concebir las variedades de la lengua no como constructos heterogéneos sino como lenguas funcionales jerarquizadas y articuladas en torno a la, en su teoría, dimensión esencial dentro del espacio de variación de las lenguas, precisamente la dimensión oral-escrito. El modelo explica, en fin, de qué modo la tripartición diasistemática coseriana se combina con y se integra en esta nueva dimensión diamedial o diaconcepcional dando lugar a los ámbitos de la inmediatez y de la distancia comunicativas ${ }^{4}$, ámbitos no opuestos, insisto, dicotómicamente sino gradualmente.

Las monografías y artículos que engloban la compleja temática de lo oral/lo hablado en lo escrito en épocas anteriores a la sincronía actual del español pueden dividirse en dos tipos de estudios: por un lado, los que se centran en documentos que, bien por la naturaleza sociolingüística del emisor, bien por la naturaleza discursiva del texto, incorporan o parecen incorporar rasgos auténticos asociados a la inmediatez comunicativa (cartas particulares, actas inquisitoriales, documentos jurídico-administrativos de diversa índole, etc. $\left.{ }^{5}\right)$. Por otro lado, los que estudian obras literarias pertenecientes a géneros (diálogo, teatro, novela, etc. ${ }^{6}$ ) en los que se produce una mimesis de la oralidad con diferencias en virtud de la época, la corriente estilística vigente, las tradiciones discursivas implicadas y la personalidad del autor (o autora).

Si tenemos en cuenta esta doble vertiente de estudio, se entenderá que mimesis de la oralidad y oralidad en lo escrito no son designaciones idénticas,

${ }^{3} \mathrm{Su}$ primera formulación data de 1985. En el ámbito hispánico la versión española de Araceli López Serena (Koch y Oesterreicher 1990[2007]) fue en gran medida responsable del éxito de la propuesta, especialmente entre los investigadores consolidados en la tradición histórico-filológica lapesiana.

${ }^{4}$ Cf. Koch y Oesterreicher (1990[2007]: 20-42; 1990[2011]: 3-20) y López Serena (2007b), para quien el modelo de los romanistas alemanes es también el más acertado para el estudio del español coloquial basado en corpus de discursos medialmente orales.

${ }^{5}$ Cf., a título de ejemplo, Oesterreicher (1994), Cano Aguilar (1996), Eberenz/De la Torre (2003), Fernández Alcaide (2008) y Almeida (2016).

${ }^{6}$ Cf. Vian (1987; 1988; 2006), Narbona (1992a; 1992b; 2001; 2005; 2012), Bustos (1993; 1996; 2001a; 2001b; 2017), Oesterreicher (2000), Cano Aguilar (2007a; 2007b), Leal Abad (2008), Del Rey (2011a; 2011b; 2015a), Méndez Orense (2016). 
sino que la última funciona como hiperónimo de la primera ${ }^{7}$ Por otro lado, en diversos lugares (cf. Del Rey 2011a: 709; 2015a: 87) he insistido en que no todo lo oral que podamos encontrar en textos literarios escritos debe identificarse con lo coloquial. En este sentido, prefiero hablar de $m i$ mesis de la conversación o verosimilitud conversacional, entendiendo por conversación un tipo de discurso en el que, según las circunstancias, concurren diferentes registros (cf. López Serena 2007a: 123-132; Del Rey 2015a: 6769 ). De este modo, una obra literaria puede recrear tanto una conversación formal como una conversación informal, si bien a los investigadores suele interesarles sobre todo esto último. En Del Rey (2011a: 709) abogo por la necesidad de no relegar a un segundo plano el estudio de rasgos propios de la distancia en el análisis del diálogo renacentista, por más que el investigador prefiera localizar fenómenos de la inmediatez que permitan establecer hipótesis sobre contextos informales de enunciación en el pasado $^{8}$. El interés despertado en las últimas décadas por el estudio de la lengua oral coloquial, alimentado por la perspectiva analítica pragmática y discursiva, ha motivado una actitud peyorativa hacia lo concepcionalmente escrito, asociado a la gramática tradicional y estructural ${ }^{9}$. Sin embargo, los estudios sobre cambio lingüístico han demostrado la importancia de la consideración del ámbito de la distancia para explicar los movimientos que se producen de arriba abajo (cf. Hausmann 1979; Labov 1994; Jacob y Kabatek 2001; Koch 2002; Pons Rodríguez 2006, 2015; Barra 2008; Del Rey 2016b), es decir, para poner de relieve cómo elementos de tradiciones discursivas de la distancia se incorporan desde este ámbito hasta alcanzar tradiciones de la inmediatez o tradiciones no marcadas concepcionalmente, funcionando así a lo largo y ancho de todo el espacio variacional de una lengua. Poco interés, no obstante, han merecido aún fenómenos de propagación de lo escrito a lo hablado en la lengua actual, motivados por la habitualización masiva de las redes sociales en nuestras formas de comunicación ${ }^{10}$. Por ejemplo, la verbalización de formas de aceptación/negación en el coloquio

${ }^{7}$ Cf. Brumme y Espunya (2011: 13). En este trabajo el lector encontrará interesantes reflexiones sobre el problema que discuto en esta introducción, aunque más ampliamente en Del Rey (2011a). Cf., asimismo, Giugliano (2012: 58-70).

${ }^{8}$ Una formulación de esta crítica también puede leerse en Cano Aguilar (2017: 280).

${ }^{9}$ Podría trazarse un paralelismo entre la falta de atención a otros registros diferentes al coloquial que evidencian propuestas teórico-metodológicas como las del Grupo Val.Es.Co. y la desconsideración de aspectos escriturales en el análisis de lo oral en lo escrito. Ambas perspectivas impiden obtener una visión de conjunto sobre la variación lingüística, de ahí la rentabilidad de la aplicación del modelo de Koch y Oesterreicher al análisis de fenómenos coloquiales u oralizantes y de fenómenos de adscripción variacional diferente. Cf., sin embargo, Briz (2010).

${ }^{10}$ Por supuesto, la lengua empleada en las manifestaciones cotidianas de la red sí está despertando un enorme interés entre los especialistas. Cf., entre otros, Mancera y Pano (2014). 
como sip y nop -esta última, seguramente calco de la negación coloquial inglesa nope en la escritura informal de blogs y plataformas como Whatsapp, Facebook y similares; la primera, tal vez forma analógica de la segunda ${ }^{11}$ es una clara muestra de cómo lo medialmente escrito y concepcionalmente hablado influye en los discursos de la inmediatez oral, algo parecido a los casos «teratológicos» que criticaba Saussure (1916[1945]: 58) a propósito del modelo ortográfico en la pronunciación francesa.

La investigación de lo oral en lo escrito lleva aparejada la incógnita de la licitud de este tipo de estudios, especialmente si lo que se persigue es describir los rasgos coloquiales que caracterizaron ciertos tipos de conversación entre nuestros antepasados. Antonio Narbona (2005: 72-73) sostiene, a propósito de la sintaxis, que el análisis de textos literarios no solo es lícito sino también necesario para desentrañar las características de la oralidad sintáctica. Por su parte, Oesterreicher (2004: 734) afirma que «lo específico del texto literario consiste exactamente en la posibilidad de fingir [...] todas las formas de[1] continuo concepcional», respaldando así análisis de esta índole ${ }^{12}$. Por compleja que pueda resultar, la aproximación a la lengua oral a través de los textos escritos es el único medio que poseemos para intentar caracterizar algunas lenguas, muy señaladamente las lenguas clásicas «muertas». Una tradición de ilustres filólogos, como Fraenkel (1922[1960]), Hofmann (1951[1978]) o Happ (1967), que escribieron sus trabajos bajo el auspicio de la Estilística como forma de explicación de la lengua hablada (cf. López Serena 2007a: 105 ss.), o más recientemente, Müller (1997) y Bagordo (2001), ha intentado determinar las características del latín hablado basándose en el testimonio de los comediógrafos preclásicos Plauto y Terencio, cuya estela es la que nos interesará en este trabajo. Happ (1967: 65 ) invoca la distinción ciceroniana entre sermo familiaris y sermo vulgaris para realizar una diferenciación diastrática entre la Umgangssprache de las

${ }^{11}$ Cabría preguntarse, sin embargo, hasta qué punto la variante escrita informal del sí afirmativo (sip) responde a la con(s) ciencia ortográfica de usuarios cultos que, al saber que el adverbio de afirmación lleva tilde, emplean la $p$ como marca diacrítica en este tipo de plataformas en las que prima la velocidad de producción del mensaje, ya que es más rápido teclear la $p$ que esperar a que aparezca el símbolo de $i$ acentuada en el teclado. Teniendo en cuenta que la forma sip es más habitual que nop en los chats españoles, podríamos preguntarnos si la analogía que se ha producido es precisamente la que lleva de sip a nop, si bien el hecho de que la marca diafásica consista en una $p$ es de difícil explicación si no se recurre al calco del inglés. Tampoco es completamente descartable la influencia lúdica de la jerigonza infantil y juvenil en la que a cada sílaba de las palabras constituyentes del mensaje se le añade una $p$ seguida de la misma vocal. Con todo, sobre todo en el español de América, muy particularmente en el de México, la adopción del nope inglés es evidente incluso en el medio oral, en el que se produce fónicamente como [nópe].

${ }^{12}$ En este sentido, Dickey (2010: 5) afirma que «in many cases, one must recognise that literary works include some language belonging to low registers». 
personas instruidas y la de las no instruidas, respectivamente ${ }^{13}$, y destaca la dificultad que entraña la tarea de tratar de hallar manifestaciones de estos registros en lenguas como el latín y el griego clásicos. El eco de la teoría de Koch y Oesterreicher resuena en la obra de Bagordo (2001), quien aprovecha la distinción medial/concepcional de los romanistas alemanes para explicar, por ejemplo, por qué los discursos de Cicerón, efectivamente pronunciados en el Senado, incluyen muchos más elementos de la distancia que testimonios escritos como las estelas funerarias.

Naturalmente, la inclusión de elementos propios de la oralidad, más o menos cercanos a la inmediatez comunicativa, en obras literarias, ya sean estas clásicas, antiguas o contemporáneas, ha de estar determinada por una criba de rasgos que permitan su fijación en el medio escrito y garanticen la legibilidad del texto ${ }^{14}$. En consecuencia, por muy «cercana» que percibamos una conversación leída en un periódico o en una novela, nunca encontraremos en ella la proliferación de interrupciones, reinicios, repeticiones, reformulaciones, etc., que se producen en el coloquio informal actual ${ }^{15}$. La mimesis conversacional siempre es producto, pues, de una (re)elaboración consciente por parte del creador ${ }^{16}$, un creador inmerso en diferentes constelaciones estilísticas y retóricas dependiendo de la época y del autor ${ }^{17}$ con

${ }^{13}$ En el concepto de latín vulgar se entrecruzan ideas pertenecientes a los niveles diafásico, diatópico y diastrático, pero es sobre todo este último el que ha pesado más en la historiografía, ya secular, del término (cf. Väänänen 1963[1981], Herman 1967[1997], Coseriu 1978 y Müller-Lancé 2006[2012]: 62-73, entre otros).

${ }^{14}$ Goetsch (1985: 202) se refiere a la naturaleza estratégica de la plasmación de la oralidad en lo escrito. La literatura exige un tipo de lectura jerarquizante (cf. Nencioni 1983: 156), jerarquía de la que carecen los registros informales de conversación. Narbona (1992a: 233) niega que en algún texto literario pueda producirse un calco de la conversación oral, ya que en él «la presencia en superficie de huellas aproximativas en el proceso de producción de enunciados forzosamente ha de reducirse y cribarse al máximo, si no se quiere que el texto provoque rechazo por parte del lector» (Narbona 2001: 199). En los mismos términos se expresan Vian (1988: 175) y Bustos (2001b: 198).

15 De ahí también que las transcripciones de conversaciones coloquiales, como las que propone el Grupo Val.Es.Co. (cf. Briz et al. 2001), sean tan diferentes en su aspecto formal de las conversaciones presuntamente coloquiales que encontramos en los textos literarios.

16 «[J]ede kunstmäßige Behandlung der 'Alltagssprache' schafft, auch wenn sie 'realistisch' vorgehen will, eo ipso eine 'Kunstsprache'» (Happ 1967: 69).

${ }_{17} \mathrm{La}$ habilidad que despliega un/a determinado/a autor/a para incluir elementos de la oralidad en su obra es clave para determinar la dialogicidad de esta, como apunta Silvia Iglesias (1998: 389): «el mayor o menor grado de dialogicidad dependerá del interés y de la sabiduría del autor para a) diversificar lo más posible el tema escogido mediante la construcción de personajes diferentes y de sus interrelaciones y la introducción de materiales extraídos de otros géneros; b) 'enmascarar' o 'justificar' la jerarquización de los participantes, y c) 'imitar' ciertas características constitutivas de los demás niveles del discurso conversacional: la contextualización del discurso, su organización lineal y jerárquica, la representación de las relaciones interpersonales y las formas de expresión lingüística». 
los que tratemos. En esa reelaboración es fundamental la vocación de crear verosimilitud $^{18}$, lo que distingue la mimesis conversacional de otros tipos de manifestación de lo oral en lo escrito.

La importancia que poseen los moldes retóricos en la escritura de lo oral (cf. Bustos 2001a: 1519) alimenta la polémica sobre si los estudios relativos a la mimesis conversacional son más propios de acercamientos literario-estilísticos o lingüísticos. Bustos (1993: 248) afirma que «dans un texte littéraire, on ne trouve pas la description d'un "état de langue", mais d'une langue "idéale", qui de toute évidence, a un statut différent de celui de la langue réelle», si bien ello no le impide describir en otros lugares características sintácticas y discursivas reales de los textos que analiza. En uno de sus últimos trabajos publicados, el profesor Bustos realiza esta rotunda afirmación:

[C] on todas las excepciones que quieran hacerse, me parece que los trabajos basados en la localización (y en su caso, descripción) de "rasgos coloquiales" en un texto no conduce $[\mathrm{sic}]$ más que a subrayar "la expresividad" de ese texto, lo que, en el mejor de los casos, es una indagación de naturaleza estilística (es decir, de estilística de la lengua o lingüística del habla en términos de Bally, de Amado Alonso, etcétera) (Bustos 2017: 223).

Cabría pensar, pues, que efectivamente Bustos confina el análisis de lo oral en lo escrito al ámbito de la Estilística. Sin embargo, esa cita se refiere exclusivamente a los estudios empeñados en hallar casi obsesivamente (cf. Cano Aguilar 2017: 280) rasgos de oralidad presumiblemente concepcional por encima de otro tipo de rasgos que, incluso si pertenecen al ámbito de la más extrema escrituralidad concepcional, conviven con estos, de ahí que sea labor indispensable del lingüista describir esta convivencia y exponerla «en un todo analítico coherente» (Bustos 2017: 223). Quizás sea esta fijación obsesiva en los rasgos coloquiales la que lleva a Bagordo (2001: 27) a afirmar que «Umgangssprache in der Literatur ist ja eher eine Frage des Stils als der Sprache» ${ }^{19}$, aseveración que implica una oposición muy cuestio-

${ }^{18}$ Cf. Del Rey (2015a: 65-69). La idea de elaboración consciente y de evocación es clave también en la definición que Brumme y Espunya (2011: 13) establecen para el concepto de oralidad fingida: «[w]e will call fictional orality in general any attempt to recreate the language of communicative immediacy in fictional texts, including both narrative and theatrical texts as well as audiovisual or multimodal texts. Fictional orality is not opposed to actual orality, but is conceived as a special technique which consists mainly of the evocation of certain characteristics of spoken communicative situations such as spontaneity, familiarity, face-to-face interaction or physical proximity» (cursivas en el original).

${ }^{19}$ Afirmación que, sin embargo, no le impide al autor caracterizar la corriente de estudios en la que se desenvuelve su propia investigación como «linguistica dialogica» (cf. Bagordo 1999). 
nable, un antagonismo indeseado, pues las corrientes estilísticas vigentes en una determinada época son fundamentales para explicar ciertos condicionamientos lingüísticos y discursivos que pueden incluso constituir el germen de cambios lingüísticos específicos ${ }^{20}$, particularmente de los que se producen de arriba abajo (cf. supra).

Sin duda el problema fundamental reside en el obstinado afán de hallar fenómenos de la inmediatez comunicativa real en textos antiguos, lo que metodológicamente, por lo demás, resulta imposible. Podemos intentar localizar «signos de inscripción oral» (Bustos 2017: 228) y postular un punto más o menos cercano al polo de la inmediatez comunicativa que asignarles a lo largo del continuum concepcional, basándonos en nuestro conocimiento de la lengua y de las variantes (morfosintácticas, léxico-semánticas, discursivo-pragmáticas) existentes para un mismo fenómeno textual ${ }^{21}$, lo que ya de por sí es útil y valioso para el historiador de la lengua. Pero de nada sirve identificar esos signos aislándolos del contexto de enunciación en que aparecen, de la(s) tradici[ó]n(es) discursiva(s) a la(s) que se asocian y de la(s) corriente(s) estilística(s) vigente(s) en un determinado momento de la historia para caracterizar un texto antiguo como oral o, lo que más arriesgado sería, coloquial. El intento de trasposición del «coloquio espontáneo» que se produce en la novela de posguerra (cf. Narbona 1992b) no es independiente de estos condicionamientos a los que acabo de aludir y, por lo demás, esa trasposición no es ajena a la inclusión de elementos

${ }^{20}$ En su estudio «Sobre problemas y métodos de una sintaxis histórica», Lapesa (2000: 62) incluye los «rasgos estilísticos [y las] preferencias o peculiaridades estéticas del lenguaje general de una época, de una escuela, de un autor» entre las competencias de la sintaxis histórica. Reproduzco, por su lucidez y pertinencia, las palabras que el profesor Cano Aguilar me transmite en comunicación personal a propósito de esta controversia: «lo que diferencia a la Lingüística de la Estilística es el punto de partida y el de llegada: el estilista se queda en la tradición retórica, en la intertextualidad literaria, en la creación de una forma individual, de escuela o de época circunscrita al lenguaje literario; el lingüista parte de las distintas conformaciones sintáctico-discursivas que se entrecruzan en el texto como producto y producción escritos (más allá y al margen de las tradiciones "literarias") y estudia cómo ello puede iluminarnos sobre los modos generales discursivos de la época, al margen o no de la tradición literaria. Al lingüista no tiene por qué interesarle el valor estético que se pueda conseguir con ello, ni el lugar de ese autor en la cadena literaria. El lingüista siempre busca el más allá de la literatura, la "lengua de todos" (al modo de cada uno)».

${ }^{21}$ El reconocimiento de las posibles variantes sintácticas y/o discursivas para una misma variable es, con todo, una tarea sumamente complicada, tal como la metodología sociolingüística ha demostrado a propósito de la determinación del entorno de variación (envelope of variation, cf. Tagliamonte 2004: 86-87), que se relaciona con el principio de accountability de Labov (1972: 72): «[o]nce we have established [the] linguistic definition of the variable, we are in a position to follow the important principle of accountability: we will report values for every case where the variable element occurs in the relevant enviroments as we have defined them». 
menos típicos de la inmediatez comunicativa ${ }^{22}$. No hay que olvidar que los intentos de plasmación o mimesis de la oralidad en la literatura son producidos por los individuos hablantes más cultos en cualquier época (cf. Kabatek 2012: 47): ellos son los que seleccionan los rasgos y los emplean en virtud del efecto comunicativo que buscan. Los rasgos que se asocian a la oralidad fingida «desempeñan funciones que pueden coincidir con las que cumplen en el lenguaje de la inmediatez comunicativa, pero también pueden ser elementos estereotipados» (Brumme 2008: 10). Mientras que en la novela contemporánea y otros géneros actuales es posible establecer esas coincidencias en virtud de nuestro conocimiento de la lengua como usuarios, las características de la inmediatez no abandonan el estatuto epistemológico de la hipótesis en el análisis de textos antiguos, medievales, renacentistas, modernos o precontemporáneos. En estos textos, además, las preceptivas retóricas tienen un peso mucho mayor que en los textos que surgen a partir de las corrientes vanguardistas de principios del siglo xx. La inclusión de «signos de inscripción» oral-coloquiales, tal como podemos encontrarlos en la novela contemporánea, es mucho más exigua en textos anteriores a la posguerra; sin embargo, existe una oralidad que podríamos denominar elaborada, una oralidad que se basa en una tradición dialógica con raíces grecolatinas ${ }^{23}$, que se erige en modelo de lengua conversacional en el primer Renacimiento (cf. Del Rey 2015a) y que ha tenido una vigencia férrea en diversos géneros literarios de la literatura hispánica hasta bien entrado el siglo $\mathrm{Xx}^{24}$.

El sentido de oralidad elaborada que utilizo aquí es solo en parte coincidente con el de «oralité elaborée» de Koch (1993: 53; «elaborierte Mündlichkeit» en Koch y Oesterreicher 2007: 357). Para estos autores, la oralidad elaborada corresponde a una de las manifestaciones de la distancia comunicativa tal como podemos observarla en la poesía oral, las fórmulas legales, los acertijos, los hechizos mágicos, etc. Dos son las reservas que planteo a esta definición del concepto: a) las realidades textuales a las que aluden los autores para ejemplificar su idea de oralidad elaborada representan formas discursivas de diferente naturaleza teórica (cf. López Serena 2011), pues

${ }^{22}$ Así lo expresa López Serena (2007a: 333): «[1] as diferencias entre conversaciones coloquiales "reales" y diálogos coloquiales "recreados" o "artificiales" se pueden ver, simplemente, como las esperables entre discursos que actualizan unidades lingüísticas adecuadas a las condiciones comunicativas en que se producen y discursos que actualizan, además, unidades inadecuadas para estas condiciones comunicativas, atraídas desde otros puntos del diasistema».

${ }^{23}$ Raíces que, a su vez, engarzan con la tradición épica de Homero y sus especiales condiciones de creación y verbalización.

${ }^{24}$ Se trata del ideal del «escribo como hablo» valdesiano, que como bien apuntó Bustos (2011), debe ser interpretado inversamente, de acuerdo con la formulación «hablo como escribo», tema que trato por extenso en Del Rey (2015b). 
los autores no hacen distingo de los géneros discursivos y de los elementos discursivo-tradicionales (cf. Winter-Froemel, López Serena, Octavio de Toledo y Frank-Job 2015) que podrían ser representativos y sintomáticos, respectivamente, de dicha oralidad elaborada, y b) relacionan el concepto exclusivamente con el ámbito de la distancia comunicativa. La oralidad elaborada a la que yo me refiero como característica del discurso dialógico y teatral, tema de este trabajo, incluye fenómenos concepcionalmente heterogéneos: por un lado, estrategias sintácticas y discursivas no adecuadas en los discursos típicamente inmediatos (cf. n. 22), entre las que cabe incluir elementos formulaicos -por ejemplo, en el inicio de turno, expresiones de aceptación argumentativa y marcadores conversacionales del tipo es verdad que, así es, está(i)s en lo cierto, decís/dices verdad, etc. (cf. Del Rey 2016a)y estrategias y elementos que imponen a la escritura dialógica un carácter impostado y retórico revelador del ideal de estilo buscado en diferentes épocas, seguramente asociado a manifestaciones de la distancia comunicativa -no necesariamente colindantes, no obstante, con el polo de la máxima escrituralidad concepcional en el continuum-. Por otro lado, esta oralidad elaborada también se caracteriza por incluir unidades prototípicas de la inmediatez o al menos no marcadas desde el punto de vista concepcional (cf. Del Rey 2020) -abundancia de elementos pronominales y adverbiales al servicio de la deixis personal, locativa y temporal; empleo de formas y modos verbales (segunda persona, imperativo, etc.) típicamente interactivos; marcadores conversacionales no ajenos a los discursos inmediatos (pues, mira, oye...), etc. (cf. Del Rey 2015a)- e incluso puede incluir estrategias que supongan concesiones, más o menos esporádicas, a lo coloquial. Estas concesiones a lo coloquial son sin duda las más difíciles de hallar y de refrendar empíricamente en los textos antiguos, pues los discursos asociados a la (máxima) inmediatez comunicativa en épocas antiguas nos son absolutamente desconocidos. Sin embargo, caracterizar en su conjunto esta oralidad elaborada, construida a partir de estrategias que pudieron o no formar parte, en menor o mayor grado, de la coloquialidad de épocas pasadas, es tarea obligatoria del lingüista, para el que también será lícito postular, dentro de este marco, la existencia de usos más o menos cercanos a la inmediate ${ }^{25}$ de

${ }^{25}$ Determinadas características, que se relacionan con las constelaciones inmediatas prototípicas (familiaridad, emocionalidad, anclaje en la situación y acción, referencialización desde el aquí y el ahora del hablante, etc., cf. Koch/Oesterreicher 1990[2007]: 34; 2011: 7), pueden ser reconocibles también en textos antiguos y, en consecuencia, ser aducidas como propias de este ámbito del continuum, siempre que no exhiban un grado de formulismo y/o retoricismo excesivo. La abundancia de rasgos presuntamente inmediatos en La lozana andaluza le permite a Bustos (2017: 226) afirmar lo siguiente: «[e]s verdad que el autor imita, pero esa imitación no procede de un modelo literario, sino que descansa en la observación de la comunicación espontánea». No obstante, ni siquiera en esta obra se puede decir que el peso de la tradición no sea importante a la hora de determinar su perfil concepcional. 
acuerdo con el conocimiento que posea de la lengua de una determinada época ${ }^{26}$. El análisis que llevo a cabo en $\S 3$ se orienta a identificar y valorar comparativamente este tipo de recursos en el corpus que describo en el siguiente apartado, si bien, insisto, un estudio más extenso debería explorar asimismo cómo los fenómenos asociados a la distancia se relacionan con otros no marcados desde el punto de vista concepcional y/o típicos de la inmediatez configurando globalmente la oralidad elaborada de un determinado texto.

\section{PRESENTACión Del CORPus: TEATRo y ORALIDAD}

En este trabajo me propongo comparar dos traducciones coetáneas de la comedia plautina Captivi con el objetivo de establecer similitudes y diferencias en la manera de plasmar la mimesis conversacional en cada uno de los autores. El más insigne de estos es don Marcelino Menéndez Pelayo, que traduce la comedia en 1879 con ocasión de su representación por parte de los alumnos de la Facultad de Letras de la Universidad Central en el Teatro Español (cf. Blanco López 2015: 301-302). Un dato que no debemos dejar pasar desapercibido, por las implicaciones que puede tener para nuestro análisis, es que la representación se llevó a cabo en latín, de manera que el texto de Menéndez Pelayo fue concebido como un apoyo para los espectadores, es decir, para que estos pudieran comprender el contenido de las intervenciones de los personajes, si bien es cierto que, en 1902, incluirá esta versión propia en su Bibliografía hispano-latina clásica (cf. Marqués López 2015: 382). El segundo traductor es Antonio González Garbín, profesor universitario almeriense, formado en Madrid y doctorado en Granada, que publica su traducción, junto con la de la Aulularia, en la Revista de Andalucía en $1877^{27}$. El origen geográfico de ambos autores puede explicar algunas de las características diatópicas que afloran en las traducciones, como el leísmo de persona y de cosa muy frecuente en Los cautivos de Menéndez Pelayo ${ }^{28}$.

${ }^{26}$ Kabatek (2014) aboga por dar valor a la capacidad interpretativa del investigador ducho en textos de una determinada época, capacidad fundada en la lingüistica empática que defiende.

${ }^{27}$ No he podido consultar esta primera edición de la traducción de González Garbín, edición exenta del prolijo aparato de notas finales que sí incluye en la impresión de 1880. En cualquier caso, consta (cf. Epistolario vol. 3, carta n. ${ }^{\circ} 304$ de 26 mayo [1879?], consultable en la BVMC) que el granadino envió a Menéndez Pelayo una copia de su traducción antes de que este realizara la suya, lo que tampoco debemos olvidar en el análisis de los textos. Sea como fuere, el santanderino no tuvo a bien incluir la versión de González Garbín en su Bibliografía (cf. Blanco López 2015: 293).

${ }^{28}$ También hay leísmo de persona en González Garbín, en convivencia con el sistema etimológico de pronombres átonos de tercera persona. El leísmo se considera en esta época un rasgo prestigioso incluso en escritores de procedencia meridional (cf. Octavio de Toledo y López Serena 2018), como es el caso de González Garbín. 
El texto teatral ha sido postulado por algunos investigadores como el género literario más apto para el estudio de la oralidad fingida o mimesis conversacional $^{29}$. Por supuesto, cabría distinguir, dentro del género teatral, entre la tragedia y la comedia: la primera, desde la clasificación de Dante, correspondiente al genus sublime; la segunda, al genus humile. Esta diferenciación retórica tiene implicaciones en la construcción del discurso en lo que atañe a la modulación de las estrategias conversacionales, pues, como apunta Oesterreicher (1996: 331), «en la comedia, que a veces se acerca a la inmediatez comunicativa, sí podemos esperar encontrar elementos de lo hablado en el sentido concepcional». No obstante, no podemos perder de vista que la comedia representa una tradición milenaria cargada de elementos estereotipados y marcas discursivo-tradicionales de difícil adscripción variacional. En el caso de las traducciones de Plauto a las que dedicamos este estudio, los rasgos de la inmediatez que podamos encontrar no dependen solo de la estrategia del traductor para la conformación del texto sino también de su actitud respecto del texto fuente, que puede variar entre el máximo respeto tendente a una literalidad excesiva hasta la consideración de la fuente como un pretexto para producir un discurso más autónomo y original ${ }^{30}$.

La obra plautina ha servido, como apunté en $\S 1$, para caracterizar la lengua hablada en el período preclásico latino ${ }^{31}$. Frente al optimismo de Happ (1969) y Hofmann (1978), para quienes la obra de Plauto constituye un corpus idóneo para la investigación de elementos coloquiales en la lengua latina, Bagordo (2001b: 297) le atribuye al comediógrafo una impronta más escritural que a Terencio, basada en la influencia de modelos griegos y en la incorporación de elementos provenientes de diversos «estratos lingüísticos» ${ }^{32}$. Es evidente que la comedia clásica, la comedia áurea o la comedia neoclásica no suponen tradiciones discursivas «bajas» sino «altas» ${ }^{33}$ y, en este sentido, no nos debe extrañar encontrar unidades prove-

${ }^{29}$ Cf., por ejemplo, Pujol (2011: 53): «[i]t is a well-known fact that theatre is the literary genre which represents fictive dialogue most clearly and most completely».

${ }^{30}$ Las dificultades que entraña la traducción de obras en las que se ve implicada la mimesis conversacional han preocupado a numerosos estudiosos, como Mayoral Asensio (1999), Del Rey (2011a), Dos Santos (2017) y los que contribuyen al volumen colectivo de Brumme y Espunya (eds.) (2011), referencia en este campo disciplinar.

${ }^{31}$ Sobre la dificultad que entraña el análisis de la oralidad concepcional en las lenguas clásicas, cf. Verano (2018: 27-29).

32 Así lo expresa también Pasquali: «tutti i personaggi [plautini] parlano lo stesso linguaggio, ma è linguaggio lontanissimo dalla lingua comune» (apud Bagordo 2001b: 297).

${ }_{33} \mathrm{O}$, en todo caso, «medias», en el sentido de que en la comedia se encuentran fenómenos que pueden ser adscritos a diferentes puntos del continuum entre inmediatez y distancia. Tomo la distinción entre tradiciones discursivas «altas» $\mathrm{y}$ «bajas» de Octavio de Toledo (2016: 81): las tradiciones «bajas» se asocian a la inmediatez comunicativa y las «altas» a la distancia. 
nientes de diferentes puntos del diasistema. Con todo, en la obra de Plauto también es posible hallar rasgos de esa oralidad elaborada que defino en $\S 1$ y que merece ser descrita para la comprensión de los fenómenos que se incorporan, a partir del texto original, en las traducciones. Por razones de espacio no nos vamos a centrar aquí en el proceso de traducción que provoca la asunción o, en su caso, la desestimación de tales rasgos, sino que nos dedicaremos a la comparación de los dos textos meta para explorar la variación concepcional intraidiomática.

Efectivamente, la traducción supone un marco de análisis inmejorable para estudios de esta índole. Generalmente, los trabajos sobre mimesis conversacional describen estrategias producidas en textos aislados, ya sean antiguos o contemporáneos, y, en este sentido, la caracterización variacional -que determina qué elementos pueden adscribirse al ámbito de la inmediatez comunicativa y qué otros al ámbito de la distancia- de estas estrategias se basa con frecuencia en la intuición ${ }^{34}$ del investigador y en su conocimiento del conjunto de la lengua o del estado de lengua que analiza. La consideración de traducciones coetáneas del mismo texto fuente nos permite investigar la variación de una manera metodológicamente más fiable, pues en dos o más traducciones del mismo texto fuente y del mismo tiempo se produce la explicitación, coincidente o divergente, de posibilidades paradigmáticas idénticas en todos los contextos de enunciación ${ }^{35}$. Esto quiere decir que podemos oponer variantes (sintácticas, léxicas, discursivas) efectivas en los diferentes textos meta y caracterizarlas relativamente para situarlas a lo largo del continuum entre inmediatez y distancia. Tanto las consideraciones cualitativas como las cuantitativas que hacemos en $\S 3$, se refieran a aspectos específicos o de conjunto, contribuyen a completar esta caracterización.

La comparación entre las dos traducciones que he presentado en este apartado tiene como objetivo describir las estrategias de mimesis conversacional en cada uno de nuestros autores, determinando el grado de inmediatez, si es posible, que puedan exhibir ciertas características sintácticas y

Una caracterización concepcional de este tipo aclararía la aparente contradicción que se lee en Sánchez (2015: 85): «los textos teatrales suelen estar escritos desde la distancia comunicativa para imitar, de forma ficticia, la inmediatez de la lengua hablada».

${ }^{34}$ Sobre la legitimidad del recurso a la intuición en la investigación histórica, cf. López Serena (2014).

${ }^{35}$ En Del Rey (2015a; 2015c) doy una muestra de la rentabilidad de este tipo de investigación. Cf. también, en el ámbito hispánico, los trabajos de Enrique-Arias (2009; 2012, entre otros). El tipo de análisis comparativo que se acomete en este trabajo viene a reconocer la importancia para la lingüística de variedades de estudios que desde el ámbito literario se han realizado tomando en consideración diversas versiones, fuentes y reelaboraciones de un mismo material de partida en distintos autores de llegada (cf. Pons Rodríguez/López Izquierdo 2017). 
discursivas. Propósito aledaño de este trabajo es contribuir a la investigación variacional de una época aún poco estudiada por los investigadores, la que continúa al «primer español moderno» (cf. Octavio de Toledo 2007; 2008; 2016) y que requiere una atención particularizada también en lo que al perfil concepcional de los textos se refiere. Se ha hablado de dos períodos clave en la inserción de elementos característicos de la inmediatez en la escritura literaria: el primero de ellos se identifica con el tránsito de la Edad Media al Renacimiento, cuando los mecanismos de textualización de la oralidad proliferan a tenor de diversos factores discursivos, lingüísticos e ideológicos (cf. Bustos 2007: 220-221); el segundo, con la llegada de la novela de posguerra (cf. Narbona 1992a; 1992b: 671), que se libera del corsé preceptista de la(s) retórica(s) vigente(s) en las corrientes literarias anteriores y que persigue la novedad de forma precisamente en el realismo conversacional. Para el español moderno, sin embargo, Kabatek (2012: 44), por ejemplo, se refiere a ciertas concesiones a la lengua coloquial en el Padre Isla que se materializan en una selección léxica innovadora y en algunas «expresiones vulgarizantes». Cabe preguntarse, así pues,

a) si la lengua conversacional que se recrea en nuestros textos puede ser sintomática de una nueva etapa en la construcción del discurso literario (pretendidamente) inmediato,

b) si la oralidad elaborada que se hereda de los modelos literarios (teatrales o dialógicos) precedentes es la que prima en la plasmación de la lengua de los personajes, y

c) si existen diferencias notables, y debidas a qué razones, en la selección de rasgos por parte de uno y otro autor.

El análisis que realizo en el siguiente apartado se orienta a dar respuesta a estas incógnitas.

\section{LA MIMESIS CONVERSACIONAL EN EL CORPUS}

En este apartado voy a comparar los resultados correspondientes a diversas variantes que considero características de contextos conversacionales inmediatos prototípicos, para caracterizarlas opositivamente. En primer lugar estudiaré algunos fenómenos que me parecen reveladores cualitativamente (\$3.1-§3.2); en segundo lugar, estudiaré otros fenómenos con más o menos detenimiento $(\$ 3.3-\S 3.5)$ ofreciendo datos cuantitativos que permitan extraer conclusiones de conjunto sobre el perfil concepcional de ambas traducciones. Por razones de espacio omito en los ejemplos la porción de texto latino fuente, una vez que he advertido (cf. supra) de que no me centraré aquí en los cambios que se producen en la construcción del 
discurso perceptibles a través del proceso de traducción, sino en la comparación entre los dos textos meta como productos de la labor traductora de Menéndez Pelayo y González Garbín. Baste decir que este último se muestra mucho menos fiel a la sintaxis del texto original que el primero, lo que probablemente tenga que ver con las diferentes condiciones de producción del texto y lo que, sin duda, motiva diferencias significativas en la construcción de la mimesis conversacional en ambos autores (cf. §4).

\subsection{Interrogación y exclamación}

Los enunciados interrogativos son inherentes a todo tipo de conversación, independientemente del registro en que se empleen. Una pregunta no solo sirve para solicitar una determinada información al interlocutor, sino que se utiliza con muy diversos fines comunicativos. Las interrogativas marcadas (cf. Escandell Vidal 1999) orientan la interpretación del enunciado condicionando la reacción del interlocutor, cuando se espera alguna, o simplemente expresan una determinada actitud (de sorpresa, indignación, recriminación, etc.) por parte del emisor, sin que reclamen respuesta alguna. Este tipo de preguntas es muy frecuente en textos escritos que recrean la realidad conversacional (cf. Iglesias Recuero 2002; Del Rey 2013), aunque se trata de estrategias que pueden localizarse en puntos muy diversos del continuum entre inmediatez y distancia (para este ámbito, piénsese en las interrogativas retóricas tan abundantes en la poesía lírica y la literatura religiosa, géneros de carácter monológico). Por lo que respecta a la exclamación, tampoco esta es ajena al retoricismo que la distancia comunicativa impone a determinados géneros textuales, si bien es un recurso muy frecuente en los discursos de la inmediatez. La abundancia de enunciados exclamativos en el nivel coloquial es en gran parte responsable de las caracterizaciones impresionistas y psicologistas que se han aplicado a este registro en tanto que imbuido de afectividad, emotividad, espontaneidad, etc., caracterizaciones heredadas de la estilística ${ }^{36}$ (cf. López Serena 2007a: 105-132).

En nuestro corpus, abundan los enunciados interrogativos y exclamativos que, en conjunto, configuran exitosamente la oralidad elaborada propia de los textos literarios precontemporáneos. Existen, en cualquier caso, algunos contextos en los que el uso de estos enunciados propicia una interpretación concepcionalmente inmediata de los recursos lingüísticos utili-

${ }^{36}$ El grado de implicación emocional y el grado de espontaneidad, de entre los parámetros que proponen Koch y Oesterreicher (1990 [2007]: 26-27; 1990[2011]: 7) para caracterizar los discursos en el marco del continuum concepcional, determinan en gran medida el uso de este tipo de estrategias. 
zados. Me refiero, en concreto, al empleo de interrogativas eco como la de (1a) y exclamativas eco como la de (2a) que podrían equipararse a las figuras en escalera que López Serena (2007a: 315-323) analiza en la narrativa española de posguerra: en el primer caso (1a), la repetición del tópico en la intervención de Filócrates ${ }^{37}$ contribuye a poner de relieve una información que creía consabida; en el segundo, la repetición ecoica representa un movimiento contraargumentativo enfático, reforzado por el siguiente enunciado igualmente antiorientado. Los puntos suspensivos que siguen a la exclamación evocan una particular modulación prosódica del inicio de turno. La traducción de Menéndez Pelayo, en ambos casos (1b y 2b), revela una sintaxis menos comprometida con la verosimilitud conversacional inmediata por lo que respecta a las variantes ecoicas que comento en este apartado, si bien el uso de un conector explicativo como es que y la construcción de la réplica mediante el conector adversativo pero seguido de la conjunción si no condicional con valor replicativo ${ }^{38}$ en $(2 \mathrm{~b})$ representan estrategias típicas de la coloquialidad que se mantienen en la conversación ordinaria de nuestros días:

(1) a. Hegion. (A Filócrates). Dime: de qué familia es ese Filócrates?

FilóCrates. De la familia Polyplusiana, que es de las más poderosas é ilustres de nuestro país.

Hegion. ¿Y á él? en qué consideracion se le tiene?

FilóCRATES. Á él? á él le dispensan las mayores atenciones los personajes primeros de la Elida $\left(\mathrm{GG}^{39}: 32\right)$.

b. Hegion. ¿De qué familia es este Filócrates?

FILóc. De la familia Polyplusia, que es la más noble y honrada de allí.

Hegion. Y él mismo, ¿en qué concepto está tenido?

FILóc. $\quad$ En el mejor concepto le tienen las personas de más valer (MP: 12).

(2) a. Hegion. Desde que le vi darte el nombre de Tindaro, me apercibi que no estaba en el uso de su razon.

Tindaro. Como que á veces se le olvida hasta su propio nombre, y no sabe decir quién es él mismo.

Hegion. Pues él se decía amigo tuyo...

TínDARO. Amigo mio!... En la vida lo he tratado... (GG: 54).

${ }^{37}$ El inicio de la intervención previa de Hegión $-i$ Y $Y$ á él? - supone no una repetición del tópico sino un cambio de tópico respecto de las dos intervenciones anteriores.

${ }^{38}$ Narbona (2008 [2015]: 96) cuestiona la interpretación de este tipo de estructuras como primitivos esquemas condicionales fragmentados que propone Montolío (1999: 59) y defiende su integridad discursiva como estrategias exclamativas propias de la oralidad.

39 Uso como convención para localizar los ejemplos las siglas GG para González Garbín y MP para Menéndez Pelayo. En el apartado de referencias bibliográficas pueden consultarse los datos específicos de publicación de las dos traducciones que analizo. 
b. Hegion. Conoci enseguida que estaba loco cuando te llamó Tyndaro.

TYNDARO. Es que á veces olvida su propio nombre y no conoce á las gentes.

Hegion. ¡Pero si decia que era amigo tuyo!

TYNDARO. Nunca vi tal (MP: 24).

\subsection{Usos del infinitivo}

Como forma regida, el infinitivo no es un elemento marcado variacionalmente, con algunas excepciones como la del infinitivo subordinado a la latina (cf. Del Rey 2016b: 94, n. 20). Algunos de sus usos independientes sí pueden asociarse a la esfera de la inmediatez comunicativa, si bien ciertas ocurrencias en el corpus evidencian un carácter estereotipado típico de la oralidad elaborada. Tal es el caso del infinitivus indignantis tan frecuente en la comedia clásica y en la retórica épica (cf. Bagordo 2001: 24, 81), que observamos en la traducción de González Garbín en (3b), frente a la solución más aséptica de Menéndez Pelayo, en el que los infinitivos son regidos:

(3) a. Hegion. La vida os vá, si no me lo quitais al punto de mi presencia!...

TYNDARO. Oh! esta es una brutal violencia, por Hércules!: arrastrarme, llevarme á empellones de esta manera... (GG: 68).

b. Hegion. ¡Ay de vosotros si no le quitáis pronto de mi presencia!

TYNDARO. Es una brutalidad arrastrarme y llevarme á empellones (MP: 31$)^{40}$.

Menos impostado resulta el uso del infinitivo en (4b), inserto en una interrogativa ecoica (cf. §3.1) que implica una respuesta negativa a la pregunta previa ${ }^{41}$, en un movimiento no ajeno, con las exigencias prosódicas oportunas, a la dinámica conversacional coloquial, si bien la variante empleada por González Garbín (4a) -repetición ecoica introducida por la conjunción que de estilo indirecto sin verbo de lengua explícito ${ }^{42}-$ también es propia de la conversación informal:

${ }^{40}$ Coincidencias en la selección léxica entre las dos versiones como la que se produce en esta intervención de Tíndaro hacen plausible la hipótesis de que Menéndez Pelayo tuviera ante sus ojos la traducción de González Garbín al elaborar su texto (cf. §2 y §4, n. 58).

${ }^{41}$ Cf. Carmona (2019: 197). Hernanz (1999: 2337) atribuye a este tipo de infinitivos un significado exploratorio o confirmativo; ejemplos como el de (4b), sin embargo, revelan un valor claramente refutativo.

${ }^{42}$ A propósito de este uso citativo del que átono en posición inicial, cf. Escandell (1999: 3979-3984) y Pons (2003: 535-537). Gras (2011) estudia este tipo de construcciones como estructuras insubordinadas. 
(4) a. ARISTOFonte. Cállate, mentido Filócrates, yo haré que seas reconocido por el verdadero Tíndaro. Por qué me estás haciendo señas? Tíndaro. Que yo te estoy haciendo señas? (GG: 58).

b. ARIST. Cállate un poco, falso Filócrates. Yo haré hoy que se encuentre al verdadero Tyndaro. ¿Qué señas me estás haciendo?

TYNDARO. ¿Yo hacerte señas? (MP: 26)

El infinitivo de mandato es difícil de encontrar en textos literarios, aunque se documenta desde la Edad Media ${ }^{43}$. Se trata de un fenómeno marcado diastrática y diafásicamente en el español actual que explota un autor como Sánchez Ferlosio en El Jarama para la caracterización del habla de sus personajes. Es sintomático de la actitud innovadora de González Garbín este uso, no esporádico, en la traducción que realiza, frente a las formas de imperativo canónicas en Menéndez Pelayo:

(5) a. El CORrector. Concedido. (Á los Cautivos). Alejaros de aquí. (Á los esclavos.) Y nosotros retirémonos un poco. (Á Filócrates). Pero os advierto que la conversacion ha de ser breve. [...] (Á los demás). Apartaros del lado de ellos (GG: 28).

b. Capataz. Sea. (A los esclavos.) Retiraos vosotros. Yo me iré tambien, pero que sea breve vuestra plática. [...] Retiraos. Dejad solos á éstos (MP: 10).

El uso del infinitivo en el enunciado exclamativo de (6a) demuestra una mayor preocupación por la selección de rasgos propios de la inmediatez por parte del autor granadino que por parte de Menéndez Pelayo (6b), en cuya traducción no hay trazas del carácter sorpresivo asociado a este uso, al que contribuye también la aparición del conector y con valor adversativo reforzador de la frustración de expectativas que se generan en el receptor en virtud del segmento discursivo precedente:

(6) a. El JEFE DE LA CATERVA. [...] y ahora vedle aquí (mostrando á Tíndaro) de siervo en la casa de su padre, y el padre sin saberlo! (GG: 12).

b. [PRólogo]. [...] éste sirve ahora en casa de su padre, sin que su padre lo sepa (MP: 2).

\subsection{La posición inicial del enunciado}

En este apartado me refiero a algunos fenómenos de sintaxis que en la bibliografía especializada, por excesiva influencia de una perspectiva escriptista en el análisis lingüístico (cf. Narbona 1988[2015]: 33-34; López

${ }^{43}$ Cf. Lapesa (2000: 834), quien advierte de que tal uso se considera vulgarismo. 
Serena 2008), han sido relacionados con la periferia izquierda de la frase y descritos como dislocaciones respecto del orden considerado «no marcado" en el español ${ }^{44}$. Tales fenómenos se identifican, en términos informativos, con tópicos y/o focos de discurso, según presenten en el contexto enunciativo una información ya conocida (temática) o nueva (remática). Las diferencias específicas entre el tópico y el foco relativas a su comportamiento sintáctico y a su estatuto informativo, sin embargo, no están claras entre los especialistas $^{45}$, de ahí que prefiera hablar en este punto, con López Serena (2012), de base como hiperónimo de los dos términos. Para esta autora, el concepto de base es muy rentable para el estudio de fenómenos relacionados con la inmediatez comunicativa ${ }^{46}$. Si bien López Serena se refiere a discursos planificados sobre la marcha en su análisis, la explotación de la posición inicial del enunciado en los textos escritos que intentan plasmar la realidad conversacional es muy recurrente.

No obstante, la naturaleza variacional de las frontalizaciones es controvertida: por lo que a los textos antiguos respecta, autores como Castillo Lluch (2015: 310 ss.) y Octavio de Toledo (2014: 303) se refieren al carácter formulaico y estilístico de algunas unidades situadas en el margen izquierdo del enunciado. Debemos, pues, pensar que se trata de estrategias aptas para discursos de cualquier perfil concepcional, que todavía en el Siglo de Oro responden a procedimientos gramaticales de estructuración informativa del enunciado en todo tipo de discursos. Con todo, es labor del lingüista determinar qué tipo de unidades suelen concurrir más habitualmente en fórmulas de topicalización/focalización y qué otras se asocian a una mayor libertad de planificación connatural a la inmediatez comunicativa. Se trate de fenómenos típicos de la inmediatez o de la distancia, la presencia de tópicos y focos en el margen izquierdo del enunciado es una característica muy grata a la oralidad elaborada, explotada con esmero, por ejemplo, en el discurso dialógico del siglo XVI ${ }^{47}$.

${ }^{44}$ Efectivamente, a pesar de que el orden de los elementos en la oración es mucho más flexible en el español que en otras lenguas, romances o no, la estructura sujeto-verbo-objeto sigue siendo considerada, explícita o implícitamente, la no marcada en nuestra lengua (cf. Borreguero 2015: 116). Para un acercamiento histórico a la noción de periferia izquierda, cf. Dufter y Octavio de Toledo (2014).

${ }^{45}$ Para los problemas relacionados con el realce informativo, la frontalización de constituyentes, la tematicidad y la rematicidad, cf. Hidalgo Downing (2003), Sornicola (2006: 376), López Serena (2012) y Octavio de Toledo (2014: 267-271).

${ }^{46}$ Cf. López Serena (2012: 321; 2017: 58). La idea de base informativa que propone la autora es muy similar a la de tema que postula Halliday (1967) y que también recupera Margarita Borreguero en algunos de sus trabajos (cf., por ejemplo, Borreguero 2006; 2018).

${ }^{47}$ Y explotada también, por cierto, en la actualidad por los guionistas españoles de series de ambientación histórica, lo que es una prueba evidente de la percepción del fenómeno como elemento discursivo-tradicional típico de la conversación miméticamente elaborada. La 
En el gráfico 1 puede apreciarse la diferencia de uso de elementos discursivos en la parte inicial del enunciado entre los dos autores que componen nuestro corpus por lo que respecta a su función sintáctica. Tanto González Garbín como Menéndez Pelayo colocan con bastante frecuencia

\section{GRÁFICO 1. Funciones sintácticas en la posición inicial de enunciado (excluyendo los sujetos no prolépticos ${ }^{48}$ )}

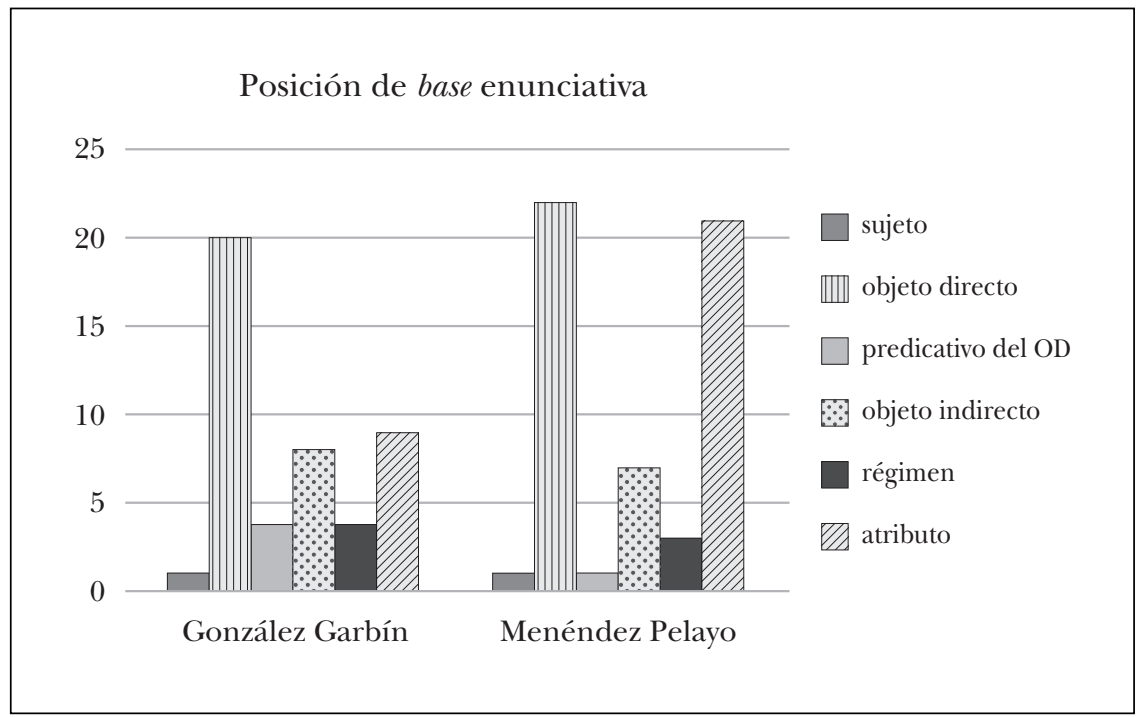

presencia del fenómeno en el diálogo del xVI es advertida también por Cano Aguilar (2016: 154), si bien, como apunto en este párrafo, la explotación de la periferia izquierda con diversos fines comunicativos es una constante en diferentes tradiciones discursivas medievales y áureas. Por lo que respecta a los adelantamientos de foco débil (cf. Gallego 2007: 221), de los que son exponente algunos de los ejemplos de esta sección, si bien su estatuto variacional puede ser variable en textos antiguos, en la época que aquí nos compete se pueden considerar, creo, estrategias propias de la escrituralidad, en la medida en que representan una técnica heredada de los escritores áureos (y clásicos) e imitada por numerosos literatos.

${ }^{48}$ Se incluyen, pues, en este gráfico los esquemas, clasificados por su función sintáctica en la oración, que representan un orden marcado de los constituyentes de acuerdo con lo apuntado en la n. 40. La función de sujeto sería, desde este punto de vista, la no marcada en esta posición, si bien he tenido en cuenta para las estadísticas frontalizaciones o prolepsis del sujeto en ejemplos como el siguiente, donde la oración de relativo precedida de $e l$ pronominal que constituye el sujeto de la oración subordinada se antepone al verbo principal, tipo de organización sintáctica, asimismo, muy grato al coloquio:

(a) Estalagmo. Oh! de ordinario olvidamos y despreciamos á aquellos de quiénes nada tenemos que esperar.

FILÓCRATES. Explícate: ¿el que tú vendiste á mi padre recuerdas bien si fué el mismo que se me dió a mi en peculio? (GG: 90 ) 
el objeto directo en la posición de base, si bien este uso, por lo general, se identifica con estrategias conversacionales no excesivamente inmediatas o no inmediatas en absoluto. De (7) a (9) relacionamos tres ocurrencias de este tipo en Menéndez Pelayo, dos de las cuales -(7) y (9)- son reflejo de la frontalización ya existente en el original latino ${ }^{49}$; de (10) a (12), otras tantas extraídas de la traducción de González Garbín, para las que cabe tener las mismas reservas en la interpretación variacional:

(7) Hegion. [...] Si me lo restituyes, aunque no me des ni un óbolo más, pondré en libertad á ti y á éste. De otro modo no puedes salir.

Tyndaro. Cosa justa me pides y eres el mejor de los hombres (MP: 14).

(8) Hegion. Muchas gracias doy á Jove y á los demás dioses por que te permitieron volver á casa de tu padre (MP: 40).

(9) Hegion. [...] Diste al traste con mi hacienda y familia por salvar á tu amo Filócrates. A él le creí siervo; á tí libre (MP: 28) ${ }^{50}$.

(10) ERGÁSILO. [...] Mi vientre y mis mandíbulas celebran hoy la gran fiesta del Hambre!... Mal háya mil veces el oficio de parásito!

(GG: 48)

(11) Filócrates. [...] ¿No tenéis más que ordenarme?

TíndARO. Que vuelvas cuanto ántes, ya lo sabes.

Filócrates. Eso no es menester advertirlo (GG: 44).

(12) Tindaro. [...] Como vos llorais á vuestro hijo, así mi padre se estará doliendo de la pérdida del suyo.

Hegion. Todo eso lo sé muy bien (GG: 36$)^{51}$.

Un uso aún más estereotipado, pero igualmente característico de la oralidad elaborada dialógica y teatral hispánica, lo constituye la anteposición del atributo al verbo copulativo ser, recurso predilecto en la versión de Menéndez Pelayo (cf. gráfico 1). En los siguientes ejemplos, observamos cómo González Garbín ofrece en contrapartida soluciones que pueden

49 Soy consciente, no obstante, de que hablar de frontalización en latín supone dar por sentado que el orden habitual de los constituyentes en esta lengua es el de sujeto-objeto-verbo (cf. Hofmann 1972: 397). Sobre orden de palabras y estructura informativa en latín, cf. Devine y Stephens (2006), Ledgeway (2012) y Danckaert (2015).

${ }_{50}$ Este tipo de tópicos contrastivos (cf. Krifka 2008: 267-268) no presentan a priori marca variacional de ningún tipo, por más que las estrategias de contraste sintáctico y/o discursivo sean frecuentes en los textos concepcionalmente orales.

${ }^{51}$ A propósito de estos dos últimos ejemplos, en tanto que incluyen estrategias de anáfora discursiva cohesionadora del texto, tampoco sería apropiado hablar de fenómenos de la oralidad concepcional, pues en términos variacionales resultan bastante neutros. 
considerarse más cercanas al polo de la inmediatez comunicativa. En (13), frente al relieve por frontalización que supone, de nuevo, un calco de la disposición de elementos desde el texto fuente en Menéndez Pidal (13b), el granadino (13a) realza el contenido de la intervención del personaje mediante la apertura de turno con el marcador interaccional de función reactiva (cf. López Serena/Borreguero 2010) mira que. En (14), la sustantivación del adjetivo en González Garbín (14a) produce una variante verosímil dentro de un registro menos retórico que el que proyecta Menéndez Pelayo (14b):

(13) a. ERgásilo. [...] Vendré entonces con los dientes calzados.

Hegion. Mira que mi comida es áspera y mala...

ERGÁsILO. Por vida mia! ¿tienes acaso por costumbre comer abrojos?

Hegion. Es que en mi mesa hace el gasto la tierra... (GG: 22-24).

b. Ergásilo. [...] Pero vendré con los dientes calzados.

Hegion. Áspera es mi comida.

ERGÁSILO. ¿Comes espinas?

Hegion. Es cena de tierra (MP: 8).

(14) a. Hegion. Que Júpiter y los dioses te confundan!...

ERgásILO. Que te confundan a ti. Por Hércules! lo justo sería que me dieras las gracias por mis noticias: tan gran provision de felicidad te traigo del puerto! con que yá me estás complaciendo $^{52} \ldots$ (GG: 80$)$.

b. Hegion. Júpiter y los demás dioses te confundan.

ERGÁsILO. ERGÁsILO. Justo es que me agradezcas la gran noticia que te traigo del puerto. Por eso vengo á comer contigo (MP: 36).

En otros casos, sin embargo, el margen izquierdo sí acoge estructuras reconocibles en los discursos coloquiales prototípicos. Tal es el caso de las

${ }^{52}$ En esta intervención de Ergásilo de la traducción de González Garbín se conjugan estrategias discursivas de diferente adscripción variacional, conjugación típica de la oralidad elaborada que describía en $§ 1$ : por un lado, elementos propios de la distancia, como los cultismos léxicos provisión y complaciendo y estructuras estereotipadas frecuentes en el diálogo de las que tratamos en este apartado, como la focalización del objeto en la oración tan gran provision de felicidad te traigo del puerto, que supone un enunciado exclamativo iniciado con la anteposición retórica del adjetivo y del indefinido tan al sustantivo; por otro, elementos coloquializadores muy efectivos, como la repetición en eco al comienzo del turno del enunciado optativo con función recriminatoria (que te confundan a ti) o como la última oración de la intervención mediante la que se exige el reconocimiento por la noticia transmitida, exigencia discursivamente formulada mediante el conector consecutivo con que seguido del adverbio ya y de la perífrasis de ser + gerundio que conmina a la realización inmediata de la petición, una estructura que sigue siendo productiva para tales fines pragmáticos en la conversación inmediata de hoy en día. El empleo del adverbio ya en este contexto y la urgencia que tal unidad imprime al acatamiento del acto de habla representa una estrategia pragmática fuertemente descortés, en tanto que supone un ataque discursivo a la negative face (cf. Brown y Levinson 1987[1996]) del interlocutor. 
construcciones de tópico contrastivo (cf. NGLE: 2556, 2983-2984) con el adverbio de polaridad positiva sí seguido de la conjunción que. Si bien, como testimonia Rodríguez Molina (2014: 885), las estructuras de sí que se documentan en el idioma a partir del siglo Xv, su empleo en tópicos constituidos por objetos pronominales en inicio de turno se explota de manera sistemática en el siglo XIX, según los datos que he podido obtener de una búsqueda no exhaustiva en CORDE, siendo muy frecuente en autores realistas como Galdós o Clarín. Este rasgo coloquializador ${ }^{53}$ de época se manifiesta en los dos autores, como se observa en los ejemplos de (15), si bien es González Garbín el más propenso a este uso, como se desprende de (16a), contexto en el que Menéndez Pelayo (16b) prefiere emplear una interrogativa retórica de menor efecto coloquial:

(15) a. Tíndaro. Despide fuego por los ojos! cuerdas, Hegion! pronto cuerdas! no ves como todo su cuerpo se tiñe de manchas lívidas? la atrabilis que le atormenta.

ARISTOFOnTE. Á tí sí que, de ejecutar este anciano lo que debe, hará que te dé tormento la pez negra, y que arrojes llamas por esa cabeza (GG: 58).

b. Tyndaro. Sus ojos están ardiendo; necesitamos una cuerda, Hegion. ¿No ves cómo se le llena el cuerpo de manchas lívidas? Está agitado por la atrabilis.

ARIST. $\quad A ́$ ti si que debe este viejo meterte en negra pez y entregarte al verdugo para que abrase tu cabeza (MP: 25).

(16) a. Tíndaro. [... lo que os acabo de manifestar á mi mismo padre se lo hubiera advertido tambien.

Filócrates. Por Pólux! Á tí sí que me atreveria yo á llamarte mi padre, porque realmente estás siendo un segundo padre para mí, querido Tíndaro (GG: 28).

b. Tyndaro. [...] Los consejos que te doy se los daria lo mismo á mi padre.

FILóc. ¿ ¿Y qué otro nombre puedo darte que el de padre pues has sido para mí padre segundo? (MP: 10-11)

Por último, la traducción de González Garbín en (17a) supone una nueva concesión del autor a la andadura sintáctica típicamente inmediata del coloquio, pues el segmento antepuesto en el margen izquierdo del enunciado produce una estructura sintáctica anómala en términos normativos, al reproducirse con clítico acusativo el complemento circunstancial de con,

${ }^{53}$ Me refiero a rasgo coloquializador para los contextos a los que aquí estoy aludiendo: relieve pronominal en inicio de turno. Como estrategias de topicalización y contraste, las construcciones de sí que pueden, sin embargo, encontrarse también en discursos típicos de la distancia comunicativa. 
muestra de la sintaxis parcelada (Narbona 1988[2015]: 42) tan frecuente en la conversación no planificada ${ }^{54}$. La solución de Menéndez Pelayo (17b) respeta la sintaxis convencional, si bien la repetición del verbo huir y el uso de la segunda persona impersonal suponen también aquí estrategias no ajenas a la conversación inmediata a la que, a veces, aspira en su comedia traducida ${ }^{55}$ :

(17) a. Hegion. [...] hombre libre cautivo es como ave salvaje... con una ocasion que se le presente de huir, la aprovecha, y, cuando el pájaro ha volado, es yá de todo punto imposible el atraparlo (GG: 18).

b. Hegion. [...] el hombre libre cuando está cautivo es semejante al ave salvaje; como se le presente una ocasion de huir huye, y nunca puedes volver á cogerla (MP: 5).

\subsection{Perifrasis de relativo}

Otro mecanismo de realce informativo, tampoco circunscrito de manera exclusiva al ámbito de la inmediatez comunicativa, lo constituyen las perífrasis de relativo, también denominadas oraciones hendidas, oraciones escindidas o estructuras ecuacionales ${ }^{56}$. Las perífrasis de relativo se componen de un verbo copulativo, un constituyente escindido que representa la magnitud que se pretende resaltar en el contexto de enunciación (cf. Gutiérrez Ordóñez 1997: 37) y la oración de relativo sin antecedente. En el gráfico 2 observamos que es González Garbín el que hace un uso más diversificado y amplio del fenómeno, lo que se comprueba en el hecho de que solo él incluye perífrasis de relativo en enunciados interrogativos, y

\footnotetext{
${ }^{54}$ No excluyo, por supuesto, la interpretación condicional del sintagma preposicional ('si se le presenta la ocasión de huir, la aprovecha'), en cuyo caso la aparición del clítico reasuntivo en la apódosis sería perfectamente normal. Sin embargo, sigo pensando que la redacción de González Garbín representa un cruce entre dos tipos de estructuras: la propiamente condicional y la de frontalización del objeto ('ocasión que se le presenta de huir, la aprovecha'). Cualquiera que sea la interpretación, en fin, el enunciado puede considerarse típico de la inmediatez comunicativa.

${ }_{55}$ Al término de este apartado, quiero reiterar mi agradecimiento a uno de los revisores anónimos de este artículo al aconsejarme que formule más explícitamente una idea que quizás solo ha sido insinuada al hilo del análisis de los ejemplos sobre base informativa: la sintaxis dialogal de González Garbín se caracteriza, en mucho mayor grado que la de Menéndez Pelayo, por el predominio tanto de la topicalización con dislocación a la izquierda (y, en ocasiones, prolepsis de sujetos de oraciones subordinadas subsiguientes) como de la focalización contrastiva.

${ }^{56}$ En inglés, cleft-sentences. Un sucinto panorama sobre la investigación acerca de estas estructuras se encuentra en Del Rey (2015d). Narbona (2000[2015]: 131-132) desaconseja la designación de hendidas y escindidas para las perífrasis de relativo de que trato en este apartado.
} 
GRÁFICO 2. Tipos de perífrasis de relativo según modalidad y función discursiva

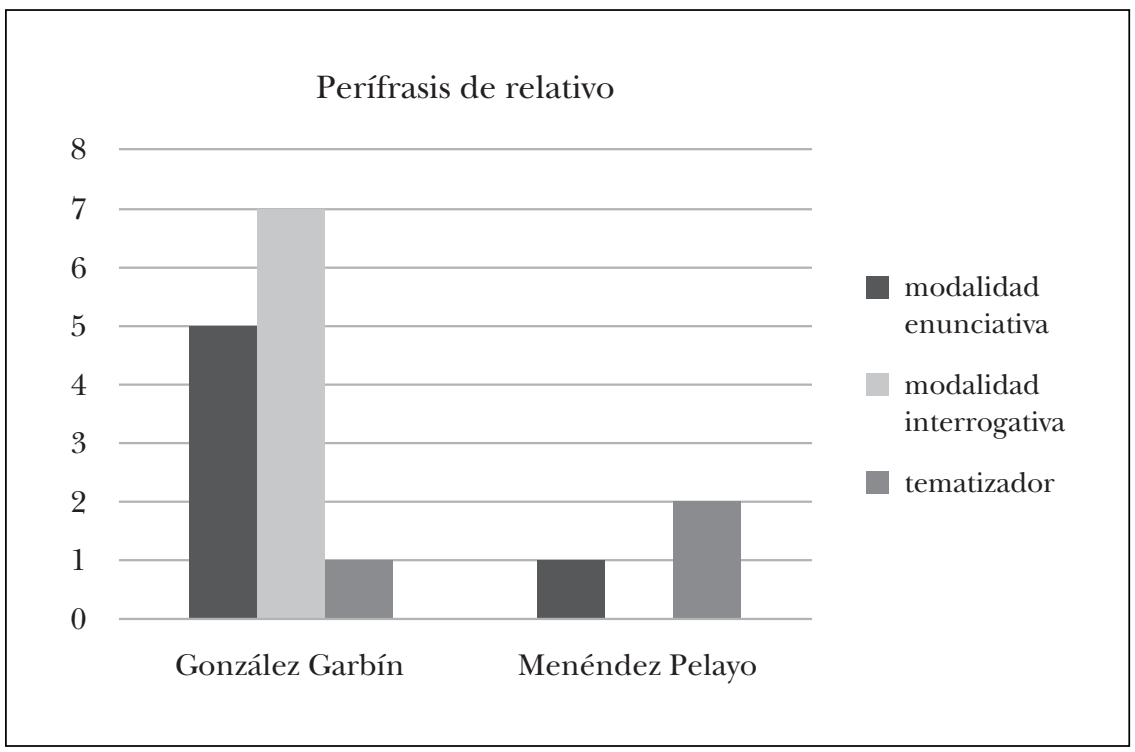

además con relativa frecuencia. Integradas en preguntas, estas estructuras pueden revestir un carácter más estereotipado o retóricamente impostado, formulaico incluso (cf. Del Rey 2015d), como cabría atribuir a la ocurrencia de (18), donde la concatenación de interrogativas en el monólogo del personaje cumple la función dramática de despertar la atención del espectador, o a la de (19), ejemplo en el que descubrimos la estructura en una pregunta relativa a los movimientos de los personajes fuera de escena, recurso de carácter igualmente monológico frecuente y casi automatizado en González Garbín para presentar la acción que está a punto de desarrollarse de cara al público:

(18) Tindaro. Ah! estoy muerto!... El enemigo se acerca, pobre Tíndaro. Qué diré? qué alegaré? qué es lo que puedo confesar? qué es lo que debo negar? No sé ¡cielos! qué resolucion tomar..... (GG: 52)

(19) Hegion. [...] No hay duda: cuando me presente en el foro, de seguro van á gritar todos: «ahí vá, ahí vá el viejo bobalicón que cree todo cuanto le dicen!». Pero no es Ergásilo ese que veo venir y que trae recogido el manto! Qué es lo que irá á hacer? (GG: 72).

En otras ocasiones, sin embargo, la utilización dentro de un enunciado interrogativo de una perífrasis de relativo en un contexto de rápida inter- 
acción dialógica sí que simula certeramente los movimientos argumentativos típicos de la modalidad coloquial, como ocurre en (20), donde la perífrasis de relativo, encabezada por el conector adversativo pero, contribuye a reforzar el paroxismo de Hegión al no comprender a qué se refiere la crítica velada que se le hace por medio de la interrogativa marcada que emplea Aristofonte en la intervención previa: la sorpresa de Hegión consiste, pues, en que Aristofonte da por sentado un contenido proposicional que le es desconocido -o, al menos, así quiere hacerlo creer el personajeal propio Hegión. Es en este tipo de contextos interactivos, cuando deseamos aclarar el contenido de una crítica, asunción, opinión, etc., que se nos achaca como propia, en los que, incluso en la conversación coloquial de hoy en día, solemos utilizar este tipo de perífrasis de relativo que ponen el foco sobre el pronombre interrogativo qué:

(20) Hegion. [...] Muchos se ven afligidos de ese mal y han encontrado en la saliva un remedio muy saludable.

ARISTOFOnte. De modo que vos creeis lo que dice ese infame?

Hegion. Pero qué es lo que yo creo?

ARIstofonte. Que yo estoy loco!! (GG: 54)

En la modalidad enunciativa, de nuevo podemos distinguir entre usos más estereotipados o, en todo caso, no marcados concepcionalmente y usos más libres y sintomáticos de una coloquialidad mimetizada. En (21a), la perífrasis de relativo sirve para seleccionar a un individuo de entre varios, aunque este mecanismo de realce informativo puede considerarse menos efectivo por lo que respecta a la elección de recursos tendentes a la textualización de la oralidad inmediata que la deixis ad oculos que se consigue mediante el demostrativo en (21b):

(21) a. Tindaro. Si enviais á cualquiera otro es como si nada hiciérais. $M i$ siervo Tíndaro es el que conviene que vaya, y yo os aseguro que, apenas haya llegado, quedará el negocio concluido (GG: 38 ).

b. Tyndaro. De nada te serviria enviar á un desconocido. Perderias el tiempo. Envia á éste: él lo hará todo en cuanto llegue (MP: 15).

En relación a los usos menos estereotipados y a pesar de que no es lo más habitual en el corpus que estoy describiendo, también es Menéndez Pelayo quien se decanta por una estrategia menos retórica que González Garbín en (22b), al introducir una perífrasis de relativo de carácter adversativo similar al que puede atribuírsele al enunciado exclamativo previo introducido por la conjunción si, igualmente de impronta coloquial (cf. n. 38), frente a la exclamación patética del personaje en el traductor andaluz $(22 a)$ : 
(22) a. Aristofonte. [...] mi amigo Filócrates se encuentra en libertad y con sus padres. ¡Cuánto me alegro!: como que á nadie quiero más entrañablemente que á él. Y ¡cuánto siento ahora el flaco servicio que he hecho al pobre Tíndaro! Por mi indiscrecion y mis palabras $\mathrm{me}^{57}$ lo cargan de cadenas!... (GG: 66).

b. ARIST. [...] Mi amigo Filócrates está libre en su patria en casa de su padre. ¡Cuánto me alegro! Si á ningún amigo quiero tanto como á él! Lo que siento es haber hecho un mal servicio á éste, que ahora por lo que yo dije está atado (MP: 29).

Con todo, la explotación de signos de inscripción coloquial-modificando ligeramente la formulación de Bustos Tovar (cf. §1) - es técnica dominada con pericia, sobre todo, por el traductor granadino. (23) es un claro ejemplo de este dominio: a pesar de que ambos autores emplean una perífrasis de relativo, la oración pseudohendida -en terminología de D'Introno (1979)seguida de la construcción coordinada opositiva que leemos en (23b), si bien no descartable en contextos de inmediatez comunicativa, no puede competir con la variante de González Garbín (23a) por lo que a la expresión de la refutación argumentativa en un registro informal se refiere. En efecto, la repetición exclamativa en eco (cf. §3.1) del último segmento de la intervención previa - un fundo- seguida de los puntos suspensivos que evocan un particular compromiso prosódico en el inicio de turno y, a continuación, la colocación del foco en el margen izquierdo (cf. §3.2) realzado por la perífrasis de relativo representan un tratamiento muy realista de la plasmación de la conversación coloquial por parte de este autor ${ }^{58}$ :

(23) a. Hegion. Vamos, decidete. ¿Quedamos convenidos?

ERGÁsILO. «Queda hecho el trato; pero con reserva de poder aceptar otros ofrecimientos si se me hicieran tales que á mi juicio y al de mis amigos fueran preferibles.» Me doyá ti mediante condiciones, como si consumáramos la venta de un fundo.

Hegion. Un fundo!... una sima sin fondo es lo que tú acabas de adjudicarme. De todas maneras, si has de venir, que vengas á la hora oportuna (GG: 22).

${ }^{57}$ La traducción de González Garbín está salpicada de dativos éticos como este (cf. NGLE: 2701-2703), otra característica de la lengua coloquial que el autor mimetiza por momentos en su texto. Por contra, no documento ocurrencia alguna en Menéndez Pelayo.

${ }^{58}$ Este ejemplo, como aduje a propósito de (14a) -cf. n. 52-, es muy representativo de la convivencia de elementos probablemente coloquiales y de otros menos adecuados desde el punto de vista concepcional en contextos supuestamente informales que es característica de la oralidad elaborada (cf. §1), tales como, en (23a), pueden serlo el juego retórico-etimológico y paronomástico entre fundo y fondo y la selección léxica, propia de la distancia, que evidencia el empleo de la voz adjudicar, frente a otras variantes menos marcadas desde el punto de vista de la variación concepcional como podrían haber sido dar o vender, que es precisamente el verbo que se emplea en el original latino. 
b. Hegion. Vamos, ¿te decides?

ERGÁsILO. Acepto la condición, si no se presenta otra más agradable para mí y para mis amigos. Yo me vendo como un fundo al primero que quiera comprarme.

Hegion. Lo que me vendes es un profundo (estómago) y no un fundo. Pero si has de venir, vente pronto (MP: 7-8).

Para cerrar este apartado me voy a referir a un tipo de construcción de pronombre relativo que se parece a las perífrasis en tanto que cumple la función de realce informativo pero que no satisface las características sintácticas que prototípicamente se asocian a las oraciones hendidas. Me refiero al uso topicalizador o tematizador de la estructura lo que es, generalmente introductora de un foco o de un tópico contrastivo. En un rastreo no exhaustivo por CORDE, he podido comprobar que este uso se atestigua ya en el siglo XVII, si bien, en las escasas ocurrencias que he documentado, siempre asociado a esquemas locativos con la preposición en. Su empleo topicalizador de pronombres (demostrativos o personales) y adverbios, aunque aparece con anterioridad, se hace frecuente solo en el siglo XIX: se encuentra abundantemente en Galdós, Pardo Bazán y Valera, y por supuesto sigue empleándose en una novela de posguerra como El Jarama. En nuestro corpus, es recurso utilizado por Menéndez Pelayo en dos ocasiones (cf. gráfico 2): en la primera (24b), la variante topicalizada del santanderino evidencia una mayor preocupación por la verosimilitud conversacional inmediata que la solución no marcada en cuanto al orden de los constituyentes de González Garbín (24a). En la segunda (25), ambas traducciones son aptas desde el punto de vista de la coloquialidad fingida: la de Menéndez Pelayo (25b), por el uso de la estrategia focalizadora que comentamos en este apartado unida al pronombre deíctico este y a la modalización que imprime al enunciado el futuro verbal; la de González Garbín (25a), por el empleo del mismo pronombre que provoca la deixis ad oculos junto con la anteposición del operador argumentativo por lo menos, del conector pues ${ }^{59}$ antiorientado al enunciado previo y de la interjección ; $a h$ ! (cf. §3.5) que, en este caso, precisamente por su relación con el siguiente pues, y a diferencia de la que abre el turno de palabra de Hegión, sí produce un efecto realista en el reflejo de una supuesta espontaneidad enunciativa:

(24) a. Hegion. Vé á ver ántes si puedes por ahí cazar una liebre; porque aquí no te espera más que un erizo: yá sabes, mi régimen habitualmente sigue una senda escabrosa.

${ }_{59}$ Por razones de espacio no he podido detenerme en este trabajo en la consideración de los marcadores discursivos, con tratamiento muy diferente en los dos traductores. Solo mencionaré un dato significativo: frente a los 41 casos de pues de inicio de turno/enunciado en González Garbín, con diversas funciones discursivas -consecutividad, réplica, reasunción temática, etc., cf. Iglesias (2000)-, solo he encontrado 8 casos en Menéndez Pelayo. 
ERGÁsILO. No has de lograr arredrarme por eso, querido Hegion: es trabajo perdido. Vendré entonces con los dientes calzados (GG: 22).

b. Hegion. Véte despues á cazar una liebre; ahora conténtate con un erizo, pues mi alimento diario es bastante duro.

ERgásilo. Lo que es en eso no me vencerás, Hegion, por mucho que lo pretendas. Pero vendré con los dientes calzados (MP: 8).

(25) a. Hegion. Ah! estos infames prisioneros se han mofado hoy de mí completamente. El uno se ha fingido esclavo y el otro ha simulado ser hombre libre... Se han comido la almendra y me han dejado en prenda la cáscara!... Imbécil! Me he dejado tiznar el rostro con toda clase de colores!... (Mirando á Tíndaro). Ah! Pues, por lo menos éste, aseguro que no se ha de burlar más de mí... (GG: 62).

b. Hegion. ¡Qué $[s i c]$ hayan podido engañarme así estos maldecidos! El uno se finge siervo, el otro libre; perdí lo principal y me quedó en prenda lo que ménos vale. Tal fué mi estolidez, que les dejé untarme á su gusto la cara; pero lo que es éste no se reirá de mí (MP: 28).

El único caso de lo que es topicalizador que se encuentra en la traducción de González Garbín es, sin embargo, de nuevo, el más revelador de una andadura sintáctica coloquial mimetizada de manera efectiva. Me refiero, en (26a), al enunciado contrastivo que se consigue mediante la adversación y la estructura de relativo que incide sobre el adverbio ahora $^{60}$, a lo que se suma la adición de los puntos suspensivos que imitan una particular cadencia prosódica antes de finalizar su aparte y que motivan la interpretación de esta intervención como un enunciado suspendido ${ }^{61}$; por su parte, Menéndez Pelayo otorga a la yuxtaposición todo el peso del valor contrastivo del enunciado, ofreciendo una traducción en la que incluso el sentido parece desvirtuado:

(26) a. Hegion. Buen parlanchin estás! quiero que nuestra conversacion sea breve, ¿lo oyes?

Estalagmo. Como os dé la gana.

Hegion. (Aparte). Cuando muchacho era dócil; pero lo que es ahora... (Á Estalagmo). Vamos al asunto: escúchame con atencion, y respóndeme punto por punto á lo que te pregunte. Si dices la verdad, cree que tu suerte será menos mala (GG: 90).

${ }^{60}$ En CREA encuentro 42 casos para la búsqueda lo que es ahora, prueba de la vigencia de esta estrategia de contraste discursivo en el español coloquial.

${ }^{61}$ Narbona (1988 [2015]: 40) advierte a propósito de este tipo de enunciados suspendidos que no deben ser considerados inacabados sino, al contrario, completos en tanto que suspendidos, y que están muy asociados al contexto de enunciación, donde se produce «el constante juego expresivo de elusión y alusión». Para una caracterización sintáctica y pragmática de algunos enunciados suspendidos, cf. Pérez Béjar (2018). 
b. Hegion. Bien hablas, pero no quiero que nuestra conversación sea larga.

Stalagmo. Sea como quieras.

Hegion. (Para sí.) Buen muchacho es, ahora no conviene. (A Stalagmo.) Ea, atiende y responde á lo que te voy á preguntar; sólo así podrá ser menos mala tu fortuna (MP: 42).

\subsection{Interjecciones}

En su estudio sobre el latín coloquial, Hofmann (1978: 9-39) incluye las interjecciones como típicas estrategias oralizantes. Por lo que respecta a las lenguas romances, no muchos dudarían en caracterizar estas unidades como propias de la conversación inmediata (cf. Koch/Oesterreicher 1990[2007]: 92-95; 1990[2011]: 60-62). Pero, de nuevo en este caso, no debemos atribuir a todas las interjecciones un estatuto variacional idéntico; de hecho, algunas de ellas solo suelen darse en discursos propios de la distancia comunicativa ${ }^{62}$. No obstante, tanto unas como otras deben formar parte de la descripción de la oralidad elaborada que he caracterizado en $§ 1$ como herramienta de ficcionalización de la conversación en la literatura ${ }^{63}$.

En el gráfico 3 se constata la diferencia cuantitativa entre ambos autores en lo que atañe al uso de interjecciones ${ }^{64}$. Las que revisten un carácter más marcadamente retórico propio de los discursos elaborados son las más frecuentes: las interjecciones que representan una invocación sobrehumana o divina (;por Pólux!, ;por Hércules!, ;cielos!) como la del ejemplo (27), son las más numerosas en González Garbín, mientras que Menéndez Pelayo muestra una predilección muy marcada por la interjección joh! (cf. n. 62). Otras

${ }^{62}$ A propósito del latín, Bagordo (2001: 24, 147) se desmarca de Hofmann al negar que interjecciones como $a h$ ! u $o h$ ! pertenezcan a la lengua coloquial latina; al contrario, serían, según el autor, marcas enunciativas empleadas en el estilo solemne propio de diversos géneros clásicos, entre ellos la poesía lírica. Para el castellano áureo, en Del Rey (2011b: 25-26) doy cuenta de la diferencia desde el punto de vista concepcional que existe entre algunas conjunciones empleadas en los diálogos de Valdés.

63 Remito a Porcar Miralles (2015) para la lectura de un breve estado de la cuestión relativo a la naturaleza discursiva y a la tipología de la interjección. Creo que el concepto de oralidad elaborada sería muy útil también para el análisis del corpus que maneja esta autora (sermones del siglo XVIII), pues, si bien, en efecto, las unidades que contempla revelan una impronta subjetiva considerable en el discurso y pueden interpretarse como signos de cooperación comunicativa, estas no son representativas de un tipo de discurso concepcionalmente inmediato.

${ }^{64}$ Incluyo en este apartado tanto elementos exclamativos de cuerpo fonético reducido -ah!, oh!, ay!-, característica que Alonso-Cortés (1999: 4025) considera definitoria de esta clase de palabras, como grupos nominales que representan fórmulas de saludo e invocaciones divinas de función discursivo-pragmática similar a la que cumplen las interjecciones propias -dioses inmortales!, por Hércules!- (cf. NGLE: 2500). 
GRÁFICO 3. Tipos de interjecciones

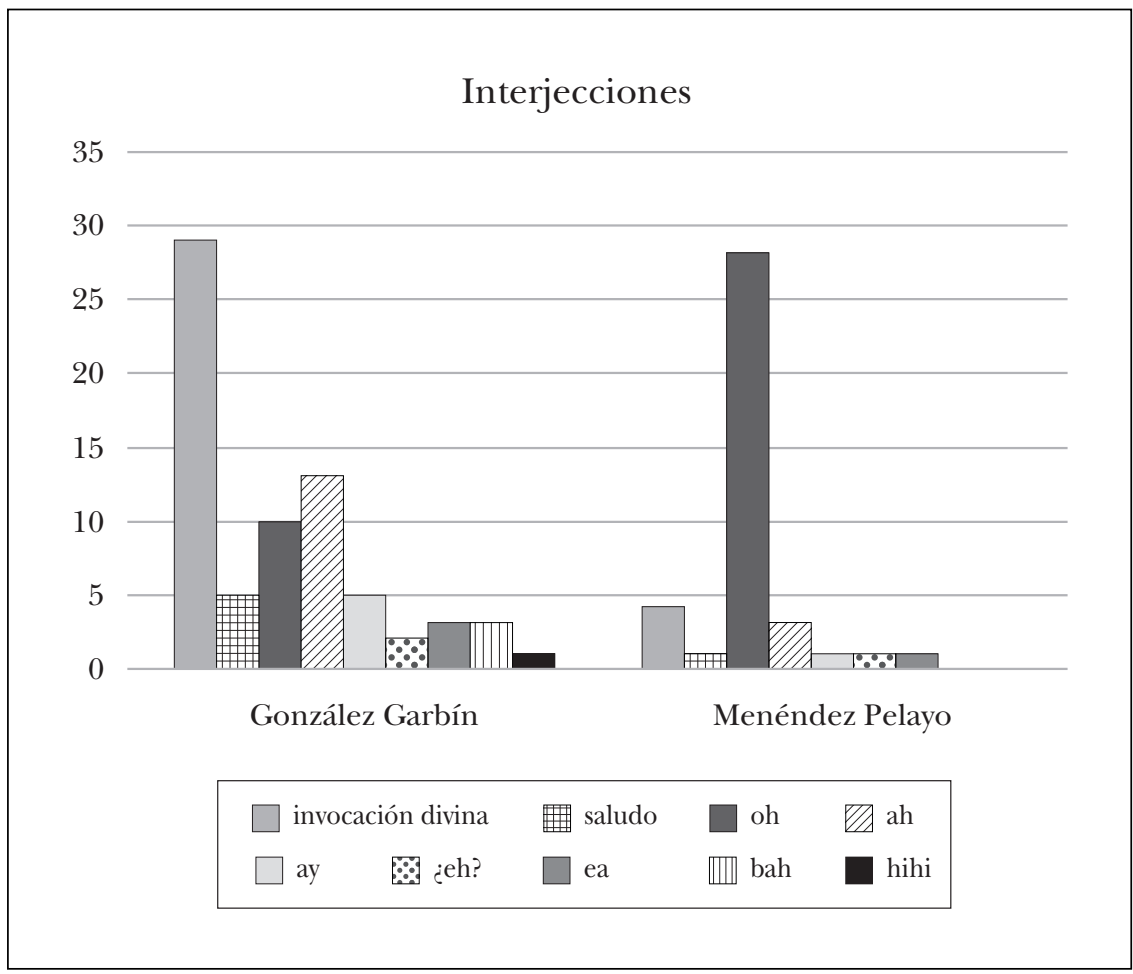

conjunciones características de los discursos de estilo elevado, como ¡ah! y ¡ay!, y fórmulas de saludo, de diferente naturaleza variacional, como ¡hola! y ¡buenos días!, se hallan también en los textos de nuestros autores.

(27) a. ARISTOFOnte. Oh dioses inmortales! acabo de penetrar este misterio!... yá lo comprendo todo! (GG: 64-66).

b. ARIST. ¡Oh dioses inmortales! Ahora comprendo de qué se trata (MP: 29).

Es, sin embargo, González Garbín el que, de nuevo, explota más frecuentemente las estrategias conversacionales propias de la inmediatez al introducir interjecciones que verbalizan determinadas emociones de los personajes que entran en escena, como ¡hihi! para la expresión del llanto ${ }^{65}$, o jea! para la de la contrariedad. Frente a estas dos unidades, cuya presen-

${ }^{65}$ A pesar de que, desde el siglo XVI, esta interjección normalmente se emplea como expresión de la risa. 
cia está suficientemente representada -sobre todo la de la segunda- en la historia del español, observamos en González Garbín el empleo de la interjección ¡bah! que, de acuerdo con los datos que arroja el CORDE, puede considerarse característica discursivo-tradicional propia de la mimesis conversacional del siglo XIX, ya que solo se documenta una ocurrencia de esta forma en Ramón de la Cruz en 1768, mientras que las 593 ocurrencias restantes pertenecen al siglo XIX -en efecto, se trata de una interjección muy usual en el diálogo de las novelas realistas-. El corpus de la RAE solo devuelve tres ocurrencias para el siglo Xx correspondientes a 1900 en la obra de Vicente Blasco Ibáñez. La aparición de la interjección en (28a) implica la banalización de la intervención precedente, en un intercambio de turnos bastante rápido en el que concurren otros signos de inscripción coloquial, como el pues de réplica de inicio de turno en la intervención anterior de Ergásilo. En Menéndez Pelayo (28b), el diálogo se desenvuelve de manera mucho más aséptica:

(28) a. ERgásILo. Por vida mia! ¿tienes acaso por costumbre comer abrojos? Hegion. Es que en mi mesa hace el gasto la tierra...

ERGÁsILO. La tierra produce javalíes...

Hegion. Y tambien muchas legumbres...

ERgásilo. Pues te las guardas para cuando haya enfermos en tu casa. Tienes algo que ordenarme?

Hegion. Que no vengas muy tarde.

ERGÁSILO. Bah! Eso se llama advertir al hombre advertido. (Váse) (GG: 24).

b. ERgÁsIlo. ¿Comes espinas?

Hegion. Es cena de tierra.

ERgásilo. Tambien es animal de tierra el cerdo.

Hegion. Tengo muchas legumbres.

ERGÁsILO. Guárdalas para curar á los enfermos de tu casa.

Hegion. Ven á tiempo.

ERGÁsILO. Nunca me olvido de esas cosas (MP: 8).

\section{ConClusiones: ¿QUÉ HaY DE MODERnO EN LA TEXTUALIZACión DE LA ORALIDAD DEL ESPAÑOL MODERNO?}

En este trabajo he querido hacer balance del concepto de mimesis conversacional, tan exitosamente explotado en diversos corpus y con diferentes propósitos en las últimas décadas $(\$ 1)$. Me he decantado por la selección del término oralidad elaborada para describir la recreación de un tipo de conversación que incluye elementos de diferentes puntos del continuum entre oralidad y escrituralidad. Este concepto permite explicar por qué determinadas estrategias que pueden tacharse de impostadas, estereotipadas, 
formulaicas, etc. (cf. §3), son igualmente sintomáticas de un tipo de discurso oralizante tal y como lo entienden los autores literarios en diferentes épocas. Asimismo, la oralidad elaborada que he descrito incorpora elementos que cabe caracterizar como típicos de la esfera de la inmediatez comunicativa, si bien en convivencia con otros que en situaciones prototípicas de interacción real coloquial resultarían inadecuados. La conjunción de elementos de diferente adscripción variacional es un rasgo inherente a esta oralidad elaborada (cf. a este respecto las observaciones hechas en las notas 52 y 58 ).

En $\$ 2$ proponía tres incógnitas que espero haber esclarecido a raíz del análisis presentado en $\S 3$. En lo que concierne a la pregunta de si puede hablarse de una nueva etapa en la selección de mecanismos de textualización de la oralidad, he advertido el uso de fenómenos que, si bien no desconocidos con anterioridad, son explotados sistemáticamente por los autores del siglo XIX, como el empleo de estructuras de tópico contrastivo con síque tras unidad topicalizada o focalizada (\$3.3), el uso de las construcciones focalizadoras o topicalizadoras con lo que es o la eclosión de la interjección ¡bah! en el diálogo decimonónico. Prácticas discursivas de esta índole, que evidencian un dominio admirable de las estrategias de la coloquialidad por escrito por parte de autores como González Garbín -un dominio poco usual en escritores de diálogos del Siglo de Oro y del siglo XVIII-, seguirán teniendo plena vigencia en la literatura española de posguerra. En este sentido, creo que cabría hablar del siglo xix como un período clave que supone un avance considerable en la utilización de los mecanismos de construcción de la oralidad elaborada, un período que quizás cabría concebir como una bisagra entre las estrategias de textualización de la oralidad que se desarrollan en el primer Renacimiento castellano, de gran vigencia en la literatura hispánica posterior, y las que cristalizan en el realismo coloquial de la novela de posguerra. Una vez más, el español moderno se revela aquí como una etapa fundamental de la diacronía del español.

Lo dicho en el párrafo anterior contesta, en parte, la segunda de las incógnitas que planteaba: la de si la mimesis de la oralidad heredada de los modelos literarios de épocas precedentes es la más reconocible en la lengua de los personajes de las traducciones que hemos considerado en §3. Por supuesto existen elementos en los textos analizados cuya presencia recuerda a la que se constata en los escritores de diálogos y en los dramaturgos áureos: construcción del discurso a base de la repetición de verbos de lengua y percepción, abundancia de diferentes tipos de interrogativas marcadas (\$3.1), fórmulas conversacionales de diverso tipo -incluidas las preguntas con perífrasis de relativo (\$3.3)-, explotación del margen izquierdo del enunciado en el inicio de turno (\$3.4), variedad de interjecciones adscribibles a un variado espectro variacional (\$3.5), etc. Sin 
embargo, aparecen innovaciones significativas, tanto cualitativas como cuantitativas, que nos permiten hablar de un nuevo capítulo de la oralidad elaborada en la literatura española ${ }^{66}$.

Por último, en la presentación del corpus (\$2), defendí la idoneidad de las traducciones que he analizado para el estudio de variantes sincrónicas reales. Por lo que respecta a la pregunta de si existen diferencias notables en la selección de estrategias conversacionales en uno y otro autor, se ha de concluir que efectivamente las hay. Si bien Menéndez Pelayo utiliza unidades que demuestran también una loable pericia en la construcción del discurso oral puesto por escrito, es González Garbín quien exhibe una mayor preocupación, en términos tanto cualitativos como cuantitativos -cf. los gráficos ofrecidos en §3-, por incluir signos de inscripción coloquial en su discurso. Ejemplos como el de (1a) y (23a) son reveladores en este sentido. Esta diferencia, que no creo que radique en la inhabilidad del santanderino para reproducir la lengua de la inmediate ${ }^{67}$, puede explicarse a partir de dos razones íntimamente relacionadas. La primera de ellas es de índole meramente traductológica: la mayor fidelidad del texto de Menéndez Pelayo al original latino bien pudo condicionar el menor uso de formas coloquiales en su versión, en la que prima el seguimiento por parte del lector del texto plautino, mientras que la mayor libertad que González Garbín imprime a su traducción le permite una mejor aclimatación de las estrategias coloquializadoras. La segunda razón, que seguramente tutele la primera, se refiere a la motivación de la escritura de ambos textos: mientras que la versión de González Garbín se ofrece como una traducción de los Captivi de Plauto seguramente pensada para la posible representación en la lengua meta -de ahí el número considerablemente superior de acotaciones escénicas en este texto-, la versión de Menéndez Pelayo se concibe como texto auxiliar durante la representación de la comedia en latín, es decir, se trata de un material de apoyo para el público. De ahí que el imperativo de la literalidad sea mucho más apremiante en Menéndez Pelayo que en González Garbín. La diferencia, con implicaciones sintáctico-discursivas específicas, puede explicarse de acuerdo con la que, parafraseando a Gregory (1967: 188-193), cabría establecer entre lo written to be read as if

${ }^{66}$ Naturalmente, merecería la pena abordar el análisis de un corpus más abundante de dramaturgia decimonónica, tanto original como traducida (muy especialmente desde obras teatrales francesas en esta época) para refrendar documentalmente esta conclusión.

${ }^{67}$ Aunque quizás sí en su aversión hacia una coloquialidad excesiva en la escritura literaria: nos consta que Menéndez Pelayo criticó las tentativas galdosianas de reproducción del habla coloquial (cf. Andrade/Alfieri 1964: 36, n. 17, apud López Serena 2007: 197). En este sentido, y sabiendo que Menéndez Pelayo recibió una copia de la traducción de González Garbín antes de que el santanderino publicara la suya, no es descartable la hipótesis de que Menéndez Pelayo intentara enmendar en su versión las libertades estilísticas del granadino. 
heard (texto de Menéndez Pelayo) frente a lo written to be spoken as if not written (texto de González Garbín) ${ }^{68}$. En cualquier caso, ambos textos ofrecen posibilidades de análisis muy ricas que reclaman una descripción no impresionista ${ }^{69}$ de la oralidad elaborada en la literatura del siglo XIX. Confiamos en que las pistas ofrecidas en este trabajo contribuyan a poblar poco a poco esta senda tan inexplorada como prometedora.

${ }^{68}$ Cabría preguntarse, como muy acertadamente me sugiere uno de los evaluadores anónimos de este trabajo, si esta diferencia puede motivar la consideración de una y otra traducción como textos pertenecientes a tradiciones discursivas distintas, cuyas características lingüísticas específicas reflejen un perfil variacional diferenciado, tal como hemos visto en este trabajo.

${ }^{69}$ No pocos estudios han abordado la lengua literaria de los autores realistas españoles, muy particularmente de Galdós, aunque mayoritariamente aplicando métodos y terminología heredados de la Estilística (cf., entre otros, Olbrich 1937; Andrade/Alfieri 1964 y Lassaletta 1974). 


\section{BIBLIOGRAFÍA}

\section{Corpus}

GG = T. Maccii Plauti, Captivi. Los cautivos. Comedia del poeta latino T. Maccio Plauto. Traduccion en lengua castellana, con abundancia de notas y comentarios por el Doctor A. Gonzalez Garbin, profesor de Literatura Clásica Griega y Latina en la Universidad de Granada. Granada: Imprenta de I. Ventura Sabatel. 1877[1880]. <http://www.bibliotecavirtualdeandalucia.es/>.

MP = Los cautivos, comedia de Marco Accio Plauto, traducida al castellano por M[arcelino] M[enéndez] P[elayo]. Representada en el Teatro Español en Diciembre de 1879 por alumnos de la Facultad de Filosofía y Letras. Madrid: Imprenta de Fortanet, Calle de la Libertad, núm. 29. 1879. <http://bdh.bne.es/>.

\section{REFERENCIAS BIBLIOGRÁFICAS}

Almeida CABRejas, Belén (2016): «Escribir lo dicho: reflejos de la lengua hablada y de los intercambios comunicativos en un corpus documental del siglo XIX", Boletín de Literatura Oral 6, 57-75.

Alonso-Cortés, Ángel (1999): «Las construcciones exclamativas. La interjección y las expresiones vocativas». En Bosque y Demonte 1999, III, 3993-4050.

Andrade Alfieri, Graciela y John J. Alfieri (1964): «El lenguaje familiar de Pérez Galdós», Hispanófila xxII, 27-37.

BAGORDO, Andreas (1999): «Lingua colloquiale e linguistica dialogica», en B. Zimmermann (ed.), Griechisch-römische Komödie und Tragödie III, Stuttgart: Metzler, 169-182.

- (2001): Beobachtungen zur Sprache des Terenz. Mit besonderer Berücksichtigung der umgangssprachlichen Elemente, Göttingen: Vandenhoeck \& Ruprecht.

BARRA JOVER, Mario (2008): «Tradición discursiva, creación y difusión de innovaciones sintácticas: la cohesión de los argumentos nominales a partir del siglo XIII», en J. Kabatek (ed.), Sintaxis histórica del español y cambio lingüistico: Nuevas perspectivas desde las Tradiciones Discursivas, Madrid/Frankfurt am Main: Iberoamericana/Vervuert, 127-149.

BÉGuelin-Argimón, Victoria, Gabriela CoRdone y Mariela DE LA TORRE (eds.) (2012): En pos de la palabra viva: huellas de la oralidad en textos antiguos. Estudios en honor al profesor Rolf Eberenz, Berlin/Frankfurt am Main: Peter Lang.

Blanco López, Salomé (2015): Plauto durante la Edad de Plata de la cultura española (1868-1936), Tesis doctoral, Madrid: Universidad Complutense de Madrid.

Borreguero ZuloAgA, Margarita (2006): «Progresión temático-remática y estructura informativa textual: convergencias y divergencias». En M. Casado Velarde, R. González Ruiz, M. ${ }^{a}$ V. Romero Gualda (coords.), Análisis del discurso: lengua, cultura, valores. Actas del I Congreso Internacional, Madrid: Arco/Libros, 205-220. 
- (2015): «El gato, que ha tirado un vaso: ¿construcciones escindidas en el español coloquial?», Revista Internacional de Lingüistica Iberoamericana (RILI) 26. Sección temática: Oraciones hendidas en el mundo hispánico: problemas estructurales y variacionales, 101-122.

- (2018): «Los encapsuladores anafóricos: una propuesta de clasificación», Caplletra 64, 179-203.

BosQue, Ignacio y Violeta Demonte (coords.) (1999): Gramática Descriptiva de la Lengua Española, Madrid: Espasa.

Briz Gómez, Antonio (2010): «Lo coloquial y lo formal, el eje de la variedad lingüística». En Rosa M. ${ }^{a}$ Castañer Martín y Vicente Lagüéns Gracia (coords.), De moneda nunca usada: Estudios dedicados a José M. ${ }^{a}$ Enguita Utrilla, Zaragoza: Instituto Fernando el Católico, 125-133.

Briz Gómez, Antonio y Grupo VAL.Es.Co. (2001): Corpus de conversaciones coloquiales, Madrid: Arco/Libros (Anejo I de Oralia).

Brown, Penelope y Stephen C. Levinson (1987[1996]): Politeness: Some universal in language usage, Cambridge: Cambridge University Press.

BRUMme, Jenny (2008): «Introducción». En J. Brumme (ed.), La oralidad fingida: descripción y traducción: teatro, cómic y medios, Madrid/Frankfurt am Main: Iberoamericana/Vervuert, 7-15.

- y Anna EsPunya (2011): «Background and justification: research into fictional orality and its translation». En Brumme y Espunya 2011, 7-31.

- y - (eds.) (2011): The translation of fictive dialogue, Amsterdam: Rodopi.

Bustos Tovar, José Jesús de (1993): «L'oralité dans les anciens textes castillans». En M. Selig, B. Frank y J. Hartmann (eds.), Le passage à l'écrit des langues romanes, Tübingen: Gunter Narr, 247-262.

- (1996): «La imbricación de la oralidad en la escritura como técnica del discurso narrativo». En Kotschi, Oesterreicher y Zimmermann 1996, 359-374.

- (2001a): «Algunos tipos de diálogos en el español del siglo XVI». En Lengua, discurso, texto. Actas del I Simposio Internacional de análisis del Discurso, Madrid: Visor/Universidad Complutense, 1515-1530.

- (2001b): «De la oralidad a la escritura en la transición de la Edad Media al Renacimiento: la textualización del diálogo conversacional», Criticón 81-82, 191-206.

- (2011): «Hablo como escribo». En Bustos Tovar, Cano Aguilar, Méndez García de Paredes y López Serena 2011, I, 459-477.

- (2017): «Oralidad y escritura en el siglo Xvi: el caso de Santa Teresa». En E. Borrego Gutiérrez y J. Olmedo Ramos (eds.), Santa Teresa o la llama permanente. Estudios históricos, artísticos y literarios, Madrid: Centro de Estudios Europa Hispánica, 221-243.

-, R. Cano Aguilar, E. Méndez García de Paredes y A. López Serena (eds.) (2011): Sintaxis y análisis del discurso hablado en español. Homenaje a Antonio Narbona, Sevilla: Secretariado de Publicaciones de la Universidad de Sevilla.

BVMC: Biblioteca Virtual Miguel de Cervantes: Epistolario de Marcelino Menéndez Pelayo según la edición de la Fundación Universitaria Española (1982-1991). $<$ http://www.cervantesvirtual.com/portales/marcelino_menendez_pelayo/epis tolario_edicion/>. 
CANO Aguilar, Rafael (1996): «Lenguaje espontáneo y retórica epistolar en cartas de emigrantes españoles a Indias». En Kotschi, Oesterreicher y Zimmermann 1996, 375-404.

- (2007b): «De nuevo sobre oralidad e historia de la lengua: el caso del Guzmán de Alfarache». En Cortés Rodríguez, Bañón Hernández, Espejo Muriel y Muñío Valverde 2007, I, 41-64.

- (2007c): «La sintaxis del diálogo en el Quijote (1605)». En Fernández Alcaide y López Serena 2007, 15-34.

- (2016): «El diálogo renacentista entre la conversación y la escritura: sobre el Diálogo de los pajes de palacio de Diego de Hermosilla». En A. M. Bañón Hernández, M. ${ }^{a}$ M. Espejo Muriel, B. Herrero Muñoz-Cobo y J. L. López Cruces (eds.), Oralidad y análisis del discurso. Homenaje a Luis Cortés Rodríguez, Almería: Editorial Universidad de Almería, 141-160.

- (2017): «A la búsqueda de los textos olvidados. Los orígenes de la modernidad discursiva en la historia del español», Romanistisches Jahrbuch 68/1, 279-301.

Carmona Yanes, Elena (2019): Tres siglos de cartas de lectores en la prensa española: estudio discursivo histórico, Berlin et al.: Peter Lang.

Castillo Lluch, Mónica (2015): «El orden de palabras en los fueros castellanos del siglo XIII». En M. López Izquierdo y M. Castillo Lluch (eds.), El orden de palabras en la historia del español y otras lenguas iberorromances, Madrid; Visor, 281-318.

CORDE: ReAl ACADEMIA EsPañola, Corpus Diacrónico del Español [en línea]. <http:// www.rae.es>.

Cortés Rodríguez, Luis, Antonio M. Bañón Hernández, M. ${ }^{a}$ del Mar Espejo MuRIEL y José Luis MuÑío VALVERde (coords.) (2007): Discurso y oralidad. Homenaje al profesor José Jesús de Bustos Tovar, I, Madrid: Arco/Libros.

COSERIU, Eugenio (1978): «Das sogenannte "Vulgärlatein" und erste Differenzierungen in der Romania». En R. Kontzi (ed.), Zur Entstehung der romanischen Sprachen, Darmstadt: Wissenschaftliche Buchgesellschaft, 257-291.

CREA: Real ACAdEmia Española, Corpus de Referencia del Español Actual [en línea]. $<$ http://www.rae.es>.

DANCKAERT, Lieven (2015): «Studying word order changes in Latin: Some methodological remarks». En C. Viti (ed.), Perspectives on Historical Syntax, Amsterdam/ Philadelphia: John Benjamins, 233-250.

Del Rey Quesada, Santiago (2011a): «Oralidad y escrituralidad en el diálogo literario: el caso de los Coloquios de Erasmo». En Bustos Tovar, Cano Aguilar, Méndez García de Paredes y López Serena 2011, II, 695-711.

- (2011b): «La verosimilitud conversacional en los diálogos de Alfonso de Valdés», Res Diachronicae IX, 7-32.

- (2013): «Traducir la pregunta: la modalidad interrogativa en las versiones castellanas de los Coloquios de Erasmo», Boletín de la Real Academia Española XCIII/CCCVIII, 433-485.

- (2015a): Diálogo y traducción. Los Coloquios erasmianos en la Castilla del s. XVI (ScriptOralia 140), Tübingen: Narr.

- (2015b): «El "latín cotidiano" como referencia estilística en la conformación del discurso dialógico castellano (s. XVI)». En Winter-Froemel, López Serena, Octavio de Toledo y Huerta y Frank-Job 2015, 209-230. 
- (2015c): «Corpus de traducción para la historia de la lengua: una cala en la prosa dialógica erasmiana», Scriptum digital 4, 37-107.

- (2015d): «¿Qué es lo que oigo? Historia de una fórmula conversacional en el diálogo literario castellano», Revista Internacional de Lingüistica Iberoamericana (RILI) 26. Sección temática: Oraciones hendidas en el mundo hispánico: problemas estructurales y variacionales, 81-100.

- (2016a): «En busca del ideal de naturalidad estilística a partir de las fórmulas de inicio de turno en el diálogo (s. XvI)», Revista de Filología Española (RFE) XCVI/1, 169-202.

- (2016b): «Interferencia latín-romance en Alfonso X: la traducción como pretexto de la elaboración sintáctica», La corónica 44/2, 75-109.

- (2020): «Lo marcado y lo no marcado en la cadena de variedades: apuntes para una nueva propuesta». En K. Grübl, T. Gruber, K. Jacob y Th. Scharinger (eds.), Was bleibt von kommunikativer Nähe und Distanz?, Tübingen: Narr (ScriptOralia) (en prensa).

Devine, Andrew M. y Laurence D. STEPhens (2006): Latin Word Order. Structured Meaning and Information, Oxford: Oxford University Press.

Dickey, Eleanor (2010): «Introduction». En E. Dickey y A. Chahoud (eds.), Colloquial and Literary Latin, Cambridge: Cambridge University Press, 3-6.

D'InTRONo, Francesco (1979): «Oraciones pseudo-hendidas y oraciones interrogativas». En F. D’Introno, Sintaxis transformacional del español, Madrid: Cátedra, 240-260.

Dos Santos, Sheila M. (2017): «Traduire l'oralité dans Grande Sertão: Veredas», Mutatis Mutandis. Revista Latinoamericana de Traducción 10, 209-230.

Dufter, Andreas y Álvaro S. OCTAVIO DE TOledo Y Huerta (2014): «Introduction». En A. Dufter y Á. S. Octavio de Toledo y Huerta (eds.), Left Sentence Peripheries in Spanish: Diachronic, Variationist and Comparative Perspectives, Ámsterdam: John Benjamins, 1-20.

EBERENZ, Rolf y Mariela DE LA TORRE (2003): Conversaciones estrechamente vigiladas. Interacción coloquial y español oral en las actas inquisitoriales de los siglos XV a XVII, Lausana/Zaragoza: Hispanica Helvetica/Pórtico.

ENRIQUe-ArIAS, Andrés (2009): «Ventajas e inconvenientes del uso de Biblia Medieval (un corpus paralelo y alineado de textos bíblicos) para la investigación en lingüística histórica del español». En A. Enrique-Arias (ed.), Diacronía de las lenguas iberorrománicas: nuevas aportaciones desde la lingüistica de corpus, Madrid/Frankfurt am Main: Iberoamericana/Vervuert, 269-283.

- (2012): «Dos problemas en el uso de corpus diacrónicos del español: perspectiva y comparabilidad», Scriptum Digital 1, 85-106.

ESCANDELL VIDAL, M. ${ }^{a}$ Victoria (1999): «Los enunciados interrogativos. Aspectos semánticos y pragmáticos». En Bosque y Demonte 1999, III, 3929-3992.

FERNÁNDEZ AlCAIDE, Marta (2009): Cartas de particulares en Indias del siglo XVI: edición y estudio discursivo, Madrid/Frankfurt am Main: Iberoamericana/ Vervuert.

- y Araceli LóPez Serena (eds.) (2007): 400 años de la lengua del Quijote. Estudios de historiografía e historia de la lengua española. Actas del V Congreso Nacional de la Asociación de Jóvenes Investigadores de Historiografia e Historia de la Lengua Espanola (Sevilla, 31 de marzo, 1 y 2 de abril de 2005), Sevilla: Secretariado de Publicaciones de la Universidad de Sevilla. 
Fraenkel, Eduard (1922[1960]): Elementi plautini in Plauto. Traducción italiana de F. Munari con añadidos del autor, Florencia: La Nuova Italia.

GALLEGO, Ángel J. (2007): «Defectivitat morfològica i variació sintàctica», Caplletra 42, 219-250.

Giugliano, Marcello (2012): Translating mimesis of orality: Robert Frost's poetry in Catalan and Italian, Tesis doctoral, Barcelona: Universitat Pompeu Fabra.

GoETsch, Paul (1985): «Fingierte Mündlichkeit in der Erzählkunst entwickelter Schriftkulturen», Poetica 17, 202-218.

Gras Manzano, Pedro (2011): Gramática de Construcciones en Interacción. Propuesta de un modelo y aplicación al análisis de estructuras independientes con marcas de subordinación en español, Tesis doctoral, Barcelona: Universidad de Barcelona.

GREGORY, Michael (1967): «Aspects of varieties differentiation», Journal of Linguistics $3 / 2,177-274$.

GutiÉRREZ Ordóñez, Salvador (1997): Temas, remas, focos, tópicos y comentarios, Madrid: Arco/Libros.

HallidaY, Michael A. K. (1967): «Notes on transitivity and theme», Journal of Linguistics 3, 199-244.

HAPP, Heinz (1967): «Die lateinische Umgangssprache und die Kunstsprache des Plautus», Glotta 45/1, 60-104.

Hausmann, Franz Josef (1979): «Wie alt ist das gesprochene Französisch?», Romanische Forschungen 91/4, 431-444.

Herman, Jozsef (1967[1997]): El latín vulgar. Versión española de M. ${ }^{a}$ C. Arias Abellán, Barcelona: Ariel.

Hernanz, M. ${ }^{a}$ Lluïsa (1999): «El infinitivo». En Bosque y Demonte 1999, II, $2197-$ 2356.

Hidalgo Downing, Raquel (2003): La tematización en el español hablado, Madrid: Gredos.

Hofmann, Johann B. (1951[1978]): Lateinische Umgangssprache, Heidelberg: Winter.

- (1972): Lateinische Syntax und Stilistik. Nueva versión revisada por A. Szantyr, Múnich: Beck.

IgLESIAS RECUERo, SiLvia (1998): «Elementos conversacionales en el diálogo renacentista». En W. Oesterreicher, E. Stoll y A. Wesch (eds.), Competencia escrita, tradición discursiva y variedades lingüisticas. Aspectos del español europeo y americano en los siglos XVI y XVII. Coloquio internacional, Friburgo 1996, Tübingen: Narr, $385-419$.

- (2000): «La evolución histórica de pues como marcador discursivo hasta el siglo XV», Boletín de la Real Academia Española, LXXX/CCLXXx, 209-307.

- (2002): Oralidad, diálogo y contexto en la lírica tradicional, Madrid: Visor.

JACOB, Daniel y Johannes KABATEK (2001): «Introducción: Lengua, texto y cambio lingüístico en la Edad Media iberorrománica». En D. Jacob y J. Kabatek (eds.), Lengua medieval y tradiciones discursivas en la Península Ibérica, Frankfurt/ Madrid: Vervuert/Iberoamericana, VII-XVIII.

KABATEK, Johannes (2012): «Corpus histórico, oralidad y oralización», en BéguelinArgimón, Cordone y De La Torre 2012, 37-50.

- (2014): «Lingüística empática», RILCE 30/3, 705-723. 
Koch, Peter (1993): «Pour une typologie conceptionnelle et mediale des plus anciens documents/monuments des langues romanes». En M. Selig, B. Frank y J. Hartmann (eds.), Le passage à l'écrit des langues romanes, Tübingen: Narr, 39-81.

- (2002): «Diachronische Varietätenlinguistik: extern und intern». En A. Wesch, W. Weidenbusch, R. Kailuweit y B. Laca (eds.), Sprachgeschichte als Varietätengeschichte/Historia de las variedades lingüisticas, Tübingen: Stauffenburg, 3-15.

- y W. OEsterReICHer (1990[2007]): Lengua hablada en la Romania: español, francés e italiano. Versión española de Araceli López Serena, Madrid: Gredos.

— y - (1990[2011]): Gesprochene Sprache in der Romania. Französisch, Italienisch, Spanisch, Berlin/Boston: De Gruyter.

— y - (2007): «Schriftlichkeit und kommunikative Distanz», Zeitschrift für germanistische Linguistik 35, 346-375.

Kotschi, Thomas, Wulf Oesterreicher y Klaus Zimmermann (eds.) (1996): El español hablado y la cultura oral en España e Hispanoamérica, Frankfurt/Madrid: Vervuert/Iberoamericana.

KRIFKA, Manfred (2008): «Basic Notions of Information Structure», Acta Linguistica Hungarica 55/3-4, 243-276.

LABOV, William (1972): Sociolinguistic patterns, Oxford: Blackwell.

- (1994): Principles of Linguistic Change, vol. 1: Internal factors, Oxford: Blackwell.

LAPESA, Rafael (2000): Estudios de morfosintaxis histórica del español. Edición de R. Cano Aguilar y M. ${ }^{\text {a }}$ T. Echenique Elizondo, Madrid: Gredos.

LAssaletta, Manuel C. (1974): Aportaciones al estudio del lenguaje coloquial galdosiano, Madrid: Ínsula.

LEAL ABAD, Elena (2008): Configuraciones sintácticas y tradiciones textuales. Los diálogos medievales, Sevilla: Secretariado de Publicaciones de la Universidad de Sevilla.

LEDGEWAY, Adam (2012): From Latin to Romance, Oxford: Oxford University Press.

López SERENA, Araceli (2007a): Oralidad y escrituralidad en la recreación literaria del español coloquial, Madrid: Gredos.

- (2007b): «La importancia de la cadena variacional en la superación de la concepción de la modalidad coloquial como registro heterogéneo», Revista Española de Lingüistica 37, 371-398.

- (2008): «El sesgo escriptista en la historia de la reflexión sobre el lenguaje y en la ciencia lingüística contemporánea: la escritura como instrumento conceptual y filtro analítico falaz», Lynx: Panorámica de estudios lingüísticos 7, 135-153.

- (2011): «La doble determinación del nivel histórico en el saber expresivo. Hacia una nueva delimitación del concepto de 'tradición discursiva'», Romanistisches Jahrbuch 62, 59-97.

- (2012): «En los márgenes de la estructura informativa: la posición inicial de enunciado como "base"», LEA: Lingüistica Española Actual 34/2, 303-337.

- (2014): «Historia de la lengua e intuición. Presentación del volumen», RILCE 30/3, 691-704.

- (2017): «Hacer (cosas con) palabras: la discursividad como universal genérico-esencial del lenguaje», Círculo de Lingüistica Aplicada a la Comunicación 69, 175-216. 
- y M. Borreguero Zuloaga (2010): «Los marcadores discursivos y la variación lengua hablada vs. lengua escrita». En O. Loureda Lamas y E. Acín Villa (coords.), La investigación sobre marcadores del discurso en español, hoy, Madrid: Arco/Libros, 325-405.

Mancera Rueda, Ana y Ana Pano Alamán (2014): El español coloquial en las redes sociales, Madrid: Arco/Libros.

MARQUÉs LóPEz, Eva (2015): Recepción e influencia del teatro de Plauto en la literatura española, Tesis doctoral, Logroño: Universidad de La Rioja.

Mayoral Asensio, Roberto (1999): La traducción de la variación lingüistica, Soria: Diputación Provincial de Soria.

MÉNDEZ OREnSE, María (2016): «Modos de reproducción del diálogo y mecanismos de cohesión dialogal en algunas Novelas ejemplares de Miguel de Cervantes», Res Diachronicae 14/1, 27-47.

Montolío, Estrella (1999): «iSi nunca he dicho que estuviera enamorada de él! Sobre construcciones independientes introducidas por si con valor replicativo», Oralia 2, 37-69.

MüLlER, Roman (1997): Sprechen und Sprache. Dialoglinguistische Studien zu Terenz, Heidelberg: Winter.

MÜLLER-LANCÉ, Johannes (2006[2012]): Latein für Romanisten, Tübingen: Narr.

NARBona JimÉNEZ, Antonio (1988[2015]): «Sintaxis coloquial: problemas y métodos». En A. Narbona Jiménez, Sintaxis del español coloquial, Sevilla: Editorial de la Universidad de Sevilla, 21-44.

- (1992a): «La andadura sintáctica coloquial en El Jarama». En M. Ariza (ed.), Problemas y métodos en el análisis de textos. In memoriam Antonio Aranda, Sevilla: Secretariado de Publicaciones de la Universidad de Sevilla, 227-260. [Ahora también en Narbona Jiménez 2015, 299-329].

- (1992b): "Notas sobre sintaxis coloquial y realismo en la literatura narrativa española». En J. A. Bartol Hernández, J. de Santiago Guervós y J. Felipe García Santos (coords.), Estudios filológicos en homenaje a Eugenio de Bustos Tovar, Salamanca: Universidad de Salamaca, I, 667-673. [Ahora también en Narbona Jiménez 2015, 299-329].

- $(2000[2015])$ : «Para una sintaxis del español coloquial». En Narbona Jiménez 2015, 117-134.

- (2001): «Diálogo literario y escritura(lidad)-oralidad». En R. Eberenz (ed.), Diálogo y oralidad en la narrativa hispánica moderna. Perspectivas literarias y lingüisticas, Madrid: Verbum, 189-208. [Ahora también en Narbona Jiménez 2015, 331-344].

- (2005): «Sintaxis de la escritura de lo oral en los diálogos del Quijote». En L. Cortés Rodríguez, A. M. Bañón Hernández, M. ${ }^{a}$ M. Espejo Muriel y J. L. Muñío Valverde (coords.), Discurso y oralidad. Homenaje al profesor José Jesús de Bustos Tovar, I, Madrid, Arco/Libros, 65-110. [Ahora también en Narbona Jiménez 2015, 257-297].

- (2008[2015]): «La problemática descripción del español coloquial». En Narbona Jiménez 2015, 92-102.

- (2012): «Diálogos bajo control». En Béguelin-Argimón, Cordone y De la Torre 2012, 247-267. [Ahora también en Narbona Jiménez 2015, 213-231].

- (2015): Sintaxis del español coloquial, Sevilla, Editorial de la Universidad de Sevilla. 
NGLE (2009): REAl ACAdEMia Española y Asociación de ACAdEMias de la Lengua EsPaÑola, Nueva gramática de la lengua española, Madrid: Espasa.

NeNCiONI, Giovanni (1983): «Parlato-parlato, parlato-scritto, parlato-recitato». En G. Nencioni (ed.), Di scritto e di parlato. Discorsi linguistici, Bolonia: Zanichelli, 126-179.

Octavio de Toledo y Huerta, Álvaro S. (2007): «Un rasgo sintáctico del primer español moderno (ca. 1675-1825): las relaciones interoracionales con interin (que)». En Fernández Alcaide y López Serena 2007, 421-442.

- (2008): «Un nuevo esquema adversativo en el primer español moderno (h. 1675-1825): la historia del nexo sino es». En C. Company Company y J. G. Moreno de Alba (eds.), Actas del VII Congreso Internacional de Historia de la Lengua, Madrid: Arco/Libros, I, 877-908.

- (2014): «Entre gramaticalización, estructura informativa y tradiciones discursivas: algo más sobre nada». En J. L. Girón Alconchel y D. M. Sáez Rivera (eds.), Procesos de gramaticalización en la historia del español, Madrid/Frankfurt: Iberoamericana/Vervuert, 263-319.

- (2016): «Aprovechamiento del CORDE para el estudio sintáctico del primer español moderno (ca. 1675-1825)». En J. Kabatek (ed.) en colaboración con C. de Benito Moreno, Lingüistica de corpus y lingüística histórica iberorrománica, Berlin/Boston: De Gruyter, 57-89.

- y Araceli López Serena (2018): «Mucho va de Hamleto a Hamlet. La lengua de las traducciones teatrales de Shakespeare por Ramón de la Cruz (atr.) y Leandro Fernández de Moratín». En S. Del Rey Quesada, F. del Barrio de la Rosa y J. González Gómez (eds.), Lenguas en contacto, ayer y hoy. Traducción y variación desde una perspectiva filológica, Bern et al.: Peter Lang (en prensa).

OESTERREICHER, Wulf (1994): «El español en textos escritos por semicultos. Competencia escrita de impronta oral en la historiografía indiana (s. XVI)». En J. Lüdtke (ed.), El español de América en el siglo XV. Actas del Simposio del Instituto Ibero-Americano de Berlin, 23 y 24 de abril de 1992, Frankfurt am Main: Vervuert, 155-190.

- (1996): «Lo hablado en lo escrito. Reflexiones metodológicas y aproximación a una tipología». En Kotschi, Oesterreicher y Zimmermann 1996, 317-340.

- (2000): «Aspectos teóricos y metodológicos del análisis del discurso desde una perspectiva histórica: el coloquio de Cajamarca de 1532». En J. J. de Bustos Tovar, P. Charaudeau, J. L. Girón Alconchel, S. Iglesias Recuero y C. López Alonso (eds.), Lengua, discurso, texto. I Simposio Internacional de Análisis del Discurso, Madrid: Visor, 159-199.

- (2004): «Textos entre inmediatez y distancia comunicativas. El problema de lo hablado escrito en el Siglo de Oro». En R. Cano (coord.), Historia de la lengua española, Barcelona: Ariel, 729-769.

OlbRich, Rolf (1937): Syntaktische-stilistische Studien über Benito Pérez Galdós, Hamburgo: Paul Evert.

PÉREz BÉJAR, Víctor (2018): «Pragmagramática de si es que: Más allá de la réplica y la justificación», Círculo de Lingüistica Aplicada a la Comunicación (CLAC) 75, 87-106.

Pons Bordería, Salvador (2003): «Que inicial átono como marca de modalidad», Estudios de Lingüistica de la Universidad de Alicante 17, 531-545. 
Pons Rodríguez, Lola (2006): «Una reflexión sobre el cambio lingüístico en el siglo XV». En Actas del V Congreso Andaluz de Lingüistica General. Homenaje a J. A. de Molina Redondo, Granada: Granada Lingvistica-Serie Collectae, III, 15631577.

- (2015): «Palabras para un ideal lingüístico: los nombres de la lengua elaborada en la historia del español», Revista de Filología Española XCV/1, 153-181.

- y Marta López IzQuierdo (2017): «Introducción. La lengua de la historia. Variaciones en la escritura del discurso historiográfico», Revista Internacional de Lingüistica Iberoamericana (RILI) 15/1, 11-16.

PorCAR Miralles, Margarita (2015): «Un recurso de oralidad en la prédica, el uso de la interjección en sermonarios del siglo XVIII», Oralia 18, 235-255.

Pujol, Dídac (2011): «The translation of fictive dialogue in theatrical plays: some metalinguistic reflections». En Brumme y Espunya 2011, 53-62.

RodRíGuez Molina, Javier (2014): «Adverbios y locuciones adverbiales de manera». En C. Company Company (dir.), Sintaxis histórica de la lengua española. Tercera parte: Adverbios, preposiciones y conjunciones. Relaciones interoracionales, México D.F.: UNAM/FCE, I, 733-937.

SÁnchez, Rosa (2015): Los géneros dialogales judeoespañoles. Oralidad fingida y variación lingüistica, Barcelona: Tirocinio.

SAUSSURE, Ferdinand de (1916[1945]): Curso de lingüistica general, traducción, prólogo y notas de Amado Alonso, Buenos Aires: Losada.

SORNICOLA, Rosanna (2006): «Interaction of syntactic and pragmatic factors on basic word order in the languages of Europe». En G. Bernini y M. L. Schwartz (eds.), Pragmatic Organization of Discourse in the Languages of Europe, Berlín: De Gruyter, 357-544.

Tagliamonte, Sali A. (2004): Analysing Sociolinguistic Variation, Cambridge: Cambridge University Press.

VÄÄNÄNEn, Veikko (1963[1981]): Introduction au latin vulgaire, París: Klincksieck. Verano Liaño, Rodrigo (2018): «The Truth Alone Will Suffice: Traces of Spoken Language in Plato's Apology of Socrates», Scripta Classica Israelica 27, 25-43.

Vian Herrero, Ana (1987): «La mimesis conversacional en el Diálogo de la lengua de Juan de Valdés», Criticón 40, 45-79.

- (1988): «La ficción conversacional en el diálogo renacentista», Edad de Oro 7, $173-186$.

- (2006): «La codificación del habla y del personaje del indio en los Coloquios de la Verdad (c. 1569) de Pedro de Quiroga». En C. Baranda Leturio y A. Vian Herrero (eds.), El personaje literario y su lengua en el siglo XVI, Madrid: Editorial Complutense, 243-283.

Winter-Froemel, Esme, Araceli López Serena, Álvaro S. Octavio de Toledo y HuERTA y Barbara FrANK-JOB (2015): «Diskurstraditionen, Diskurstraditionelles und Einzelsprachliches im Sprachwandel: Zur Einleitung/Tradiciones discursivas, tradicionalidad discursiva e idiomaticidad en los procesos de cambio lingüístico. Introducción». En Winter-Froemel, López Serena, Octavio de Toledo y Huerta y Frank-Job 2015, 1-27.

Winter-Froemel, Esme, Araceli López Serena, Álvaro S. Octavio de Toledo y HuERTA y Barbara Frank-JoB (eds.) (2015): Diskurstraditionelles und Einzelsprachliches im Sprachwandel, Tübingen: Narr. 